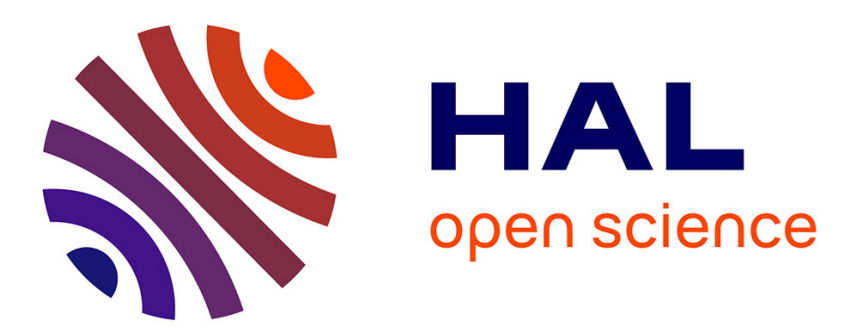

\title{
Mechanical analysis of a mixed mode debonding test for composite pavements
}

Armelle Chabot, Ferhat Hammoum, Manitou Hun

\section{To cite this version:}

Armelle Chabot, Ferhat Hammoum, Manitou Hun. Mechanical analysis of a mixed mode debonding test for composite pavements. Construction and Building Materials, 2013, 40, p.1076-1087, fig., graphiques, ill. en couleurs, bibliogr. 10.1016/j.conbuildmat.2012.11.027 . hal-00845901

\section{HAL Id: hal-00845901 \\ https://hal.science/hal-00845901}

Submitted on 18 Jul 2013

HAL is a multi-disciplinary open access archive for the deposit and dissemination of scientific research documents, whether they are published or not. The documents may come from teaching and research institutions in France or abroad, or from public or private research centers.
L'archive ouverte pluridisciplinaire HAL, est destinée au dépôt et à la diffusion de documents scientifiques de niveau recherche, publiés ou non, émanant des établissements d'enseignement et de recherche français ou étrangers, des laboratoires publics ou privés. 


\title{
Mechanical analysis of a mixed mode debonding test for "composite" pavements
}

\author{
A. Chabot*, M. Hun, F. Hammoum \\ LUNAM Université, IFSTTAR, CS4, F-44341 Bouguenais, France \\ *Corresponding author: armelle.chabot@ifsttar.fr
}

\begin{abstract}
:
In order to investigate interlayer debonding near skrinkage cracks or joints of "composite" pavements, a four-point bending test on bi-layer structures is performed. Before mixed mode failure, the quasi-analytical calculations obtained by a specific elastic model match experimental results under static and controlled displacement conditions. Both the interface normal and shear stress intensities determined at the specimen edge lie within the range of values found in the literature for cement concrete overlays on a bituminous material type of interface. The strain energy release rate is calculated. Results are discussed relative to both data provided in the literature and testing campaigns.
\end{abstract}

Keywords: crack, interface debonding, modeling, composite pavement, four-point bending test.

\section{Introduction}

To ensure a long lasting pavement, high bond strengths between pavement layers are obviously required. The importance of establishing a good bond between pavement layers is clearly obvious between bituminous layers and a bituminous material as well as a cement concrete layer. During the pavement service life however, due to the structural heterogeneity of multilayer systems, debonding between pavement layers can occur, especially near the edges or vertical cracks through one layer. This phenomenon has been closely observed near joints of UltraThin White-topping pavements (UTW) [1-3] or near reflective cracks of composite pavement [4] during certain experiments, all conducted using the accelerated pavement loading facility. For these two types of "composite" pavements made both with bituminous and cement concrete layers, vertical discontinuities typically originate from shrinkage effects or joints in the cement concrete layer. To complete a study of crack initiation and propagation within the structure, a specific model and experimental device dedicated to characterizing interface behavior between pavement layers near shrinkage 
cracks or joints, needs to be introduced. It implies that a mechanical analysis on bi-material systems must be performed, as is the case for other applications that usually use bending tests (see, for example, [5-7]). In order to investigate the properties of pavement interfaces, a number of experimental works carried out in the past mainly for reflective crack studies [8-13] may contribute to the knowledge. When characterizing the buckling-delamination that occurs in the tack coat material placed at the interface between two bituminous material layers or between a bituminous material overlay and a ciment concrete layer, interested readers are referred to recent literature in either pure debonding mode (mode I) [14] or pure shearing mode (mode II) [15-20], exclusively. For a characterization of cement shrinkage or other effects on bonding between a cement substrate and a cement concrete layer, recent results displayed in [21-25] also provide insight about bending tests. As regards the mechanical characterization of interfaces between the cement concrete overlay and the bituminous material layer, the data given in [1] illustrate (see Table 1 below) the results derived from the literature on both field and laboratory measurements. For this last type of interface in particular however, the problem has not yet been fully investigated.

These data fall in the same range as those obtained in 3D elastic simulations run for a standard French load of 32,500 $\mathrm{N}$ uniformly distributed over a rectangular area at the edge of a joint on an Ultra Thin Whitetopping pavement [32-33].

This paper is primarily focused on investigations to determine mixed mode fracture resistance of bi-material interfaces made with bituminous and cement concrete materials. Depending on which material is chosen as the overlay, the mechanical advantage of combining bituminous material and cement concrete layers is in fact to reduce both the effect of the existing vertical crack, resulting from the shrinkage phenomenon of cement concrete layers, and the rutting phenomenon generated from the bituminous material. In France, even though this latter type of pavement, called Ultra-Thin Whitetopping (UTW), is not commonly used, it may become more frequently dedicated to urban applications. Regardless of the type of interface and treatment used however, the reflective, debonding or corner crack phenomenon in slabs may indeed occur [12, 31]. In fact, as for edge delamination in composite field, existing joints or vertical cracks in a pavement layer create such a high concentration of both normal and shear interface stresses that the crack could propagate along the interface between the two different layers before penetrating through one of the materials or even debonding elsewhere far from them [1-4, 32-33]. The modulus ratio between layers, due to the variation in temperature 
effect and the loading rate on mechanical properties of bituminous material as well as to the position of the load close to the vertical crack, plays an important role in the long-term performance of the bond [3-4]. Following the laboratory testing campaign [1] and results stemming from other applications [5-7, 21-25, 34], a four-point bending test (4PB), used on concrete beams strengthened by externally-bonded plates, has been adapted for the pair of bituminous and cement concrete materials [35] (see Fig. 1). The aim of this paper is to explain the approach adopted here to optimize the test in order to take into account the local stress around the edge of the interface bond. The advantage of this test is to be able to investigate the mechanical properties of interfaces under mixed mode conditions without using any supports or applied any loads directly on the bituminous material. The main objectives of this paper are so to present preliminary results to investigate and to analyse, with the following points, if:

1. This 4PB test may be adapted and used to study the debonding phenomenon in a bi-layer material composed with a cement concrete and a bituminous material.

2. A specific elastic Multiparticular Model which can simulate the 3D interface stress in cracked pavements [33] may be used in this investigation.

3. The elastic modeling combined with the experimental test can provide interesting information at a macro scale on interface fracture in mixed mode condition; the elastic assumption may be adopted here if one considers that the initial response of the bi-layer specimen is not affected by the viscoelasticity of the bituminous materials.

The first section of this paper will present the dedicated model used to simulate the mechanical field at the interface between composite layers. This model's equations will be solved on the four-point bending test, as illustrated on Figure 1. The two materials are considered to be homogeneous and isotropic. Mixed mode fracture mechanisms on the interface between layers are to be anticipated. By means of a specific modeling approach, convergence of the interface stress field near the edge will be shown. An analytical expression of the strain energy release rate for each fracture mode will be given as a function of both material parameters and interfacial stresses. For materials tested in the laboratory, static elastic simulations will be run with the aim of optimizing specimen geometry in order to favor the delamination phenomenon. Experimental results, mainly obtained under controlled displacement conditions $(0.7 \mathrm{~mm} / \mathrm{min})$, will be given for two types of interfaces. Lastly, according to these experimental observations and data, an initial simplified and elastic mechanical interpretation of results will be provided. 


\section{Simulations}

This section will discuss the elastic simulations conducted for multilayer structures made from homogeneous and isotopic materials. The first subsection will present the specific model used to derive the mechanical interface field at the edge location before its application to the four-point bending test. Next, for the materials tested herein, simulations will be run for the purpose of designing bi-material specimens. These simulations will also be useful for the developments in Section 3, as well as for the discussion provided on experimental results under static conditions for two different temperature values.

\subsection{The multi-particle model of multilayer materials with 5 equilibrium equations per layer (M4-5n)}

An analysis of the delamination phenomenon on a multilayered system leads to studying a singular stress field at both the interface and edge location between two materials. By introducing classical modeling techniques, the calculation of energy release rates does not converge. This non-convergence is due to oscillatory singularities around the crack tip [36]. Even though these irregularities are confined to very small regions near the end of the crack, this phenomenon does not convey any physical meaning [37]. Some solutions may be found in the literature [38-41]; however, the use of conventional crack criteria remains quite complex [42-43] and finite element simulations are usually "cumbersome" to implement and expensive for common application by engineers.

The family of multi-particle models of multilayer materials (M4) has been specially developed to study edge effects in composite structures [44-46]. As opposed to other classical models, these mechanical models yield finite stresses at a free edge or crack tip at the interface point location of two different layers. This modeling approach avoids singularities and reduces the real one-dimensional problem that accelerates the equation resolution process compared to other modeling approaches. The interested reader should refer to [46] for a complete description of this topic.

The M4 selected herein for the pavement bending problem contains five kinematic fields per layer $i$

( $i \in\{1, \ldots, n\}$, where $n$ denotes the total number of layers): average plane displacements $U_{\alpha}^{i}(x, y)$; the average out-of-plane displacement $U_{3}^{i}(x, y)$; and average rotations $\Phi_{\alpha}^{i}(x, y)$, where $(x, y)$ represent the layer's plane coordinates and the $\alpha$-plane directions $(\alpha \in\{1,2\})$. This model is labeled M4-5n. The M4-5n 
construction is based on a polynomial approximation per each layer of degree 1 in $z$ (vertical direction) for the in-plane stress fields. According to the equilibrium equations, this set-up provides, for each layer, a $2^{\text {nd }}$ degree polynomial equation in $z$ for shear stresses and a $3^{\text {rd }}$-degree equation in $z$ for the normal stress. The coefficients of these polynomial approximations are $(x, y)$ fields per layer $i$; they are expressed via the classical Reissner generalized stress fields. These polynomial approximations offer the advantage of defining the out-of-interface plane normal $v^{i, i+1}(x, y)$ and shear stresses $\tau_{\alpha}^{i, i+1}(x, y)$ at interface $i, i+1$ (and similarly $i$ 1,i), between layers $i$ and $i+1$ (and similarly between layers $i-1$ and $i$ ). Hellinger-Reissner's formulation [47] reduces the real 3D problem to a determination of regular plane fields $(x, y)$ per each layer $i$ and interface $i, i+1$ (and $i-1, i)$. This model may be viewed as a superposition of $n$ Reissner plates connected by means of an elastic energy that depends on the interlaminar stress fields. For plane strain tension problems, the stress fields are obtained very quickly and lie very close to those resulting from 3D finite element calculations [48]. For crack initiation problems, delamination criteria in the angle-ply laminates have been proposed [46, 4950]. Two such criteria can be used for pavement problems. The first one is based on the maximum values of interface stresses, as evaluated by M4-5n. The second criterion is based on an analytical calculation of the individual strain energy release rates within a delaminated multilayer structure.

\subsection{M4-5n equations applied to the 4PB test}

In order to simplify the analysis, the 4PB test on a bi-layer specimen, as illustrated in Figure 1, has been simulated under the assumption of plane strain conditions. Subsequently, the mechanical fields of the M4-5n depend solely on variable $x$. The materials are considered to be elastic, homogenous and isotropic. The layer

" $i^{\prime \prime}(i \in\{1,2\})$ is characterized by $e^{i}, \rho^{i}, E^{i}, v^{i}$, i.e. its thickness, density, Young's modulus and Poisson's ratio parameters, respectively. The problem can be divided into three zones (Fig. 1a). The first and last zones, where $x \in\left[0, a_{1}\right]$ and $x \in\left[L-a_{2}, L\right]$, are composed of just the single number 2 layer. By means of shear forces, these zones allow analytically transmitting, at $x=a_{1}$ and $x=L-a_{2}$, the linking conditions of displacements, forces and moments between the various zones, in addition to support conditions of the beam with respect to the bi-layer zone (i.e. where $x \in\left[a_{1}, L-a_{2}\right]$ ). On this central bi-layer zone, a series of equation manipulations ultimately lead to solving a second-order system of differential equations that are solely a function of $\mathrm{x}$, as written in the following expression (1): 


$$
A X^{\prime \prime}(x)+B X(x)=C \text { with } X(x)=\left(\begin{array}{c}
U_{1}^{1}(x) \\
\Phi_{1}^{1}(x) \\
Q_{1}^{1}(x) \\
U_{1}^{2}(x) \\
\Phi_{1}^{2}(x)
\end{array}\right)
$$

where $\mathrm{A}, \mathrm{B}$ and $\mathrm{C}$ are the analytical matrix functions of geometric parameters, the elastic characteristics of material behavior, and the loading conditions specified in Figure 1, respectively. The expressions of A, B, and $\mathrm{C}$ are given in (2-4) where $F_{3}^{i}=\rho^{i} e^{i} b \times g \quad\left(g=9.81 \mathrm{~m} / \mathrm{s}^{2}\right)$ represents the dead weight of the layer i $(i \in\{1,2\})$.

$$
\begin{aligned}
& -\frac{e^{1^{2}} E^{1}}{2\left(1-v^{1^{2}}\right)} \quad \frac{e^{1^{3}} E^{1}}{12\left(1-v^{2^{2}}\right)} \\
& \frac{4}{15}\left(\frac{e^{1^{2}}}{\left(1+v^{1}\right)}+\frac{e^{1} e^{2} E^{1}\left(1+v^{2}\right)}{E^{2}\left(1-v^{1^{2}}\right)}\right) \\
& A=\left(\frac{e^{1}}{5\left(1+v^{1}\right)}-\frac{e^{1} E^{1}\left(1+v^{2}\right)}{5 E^{2}\left(1-v^{1^{2}}\right)}\right) \\
& 0 \\
& 0 \\
& -\frac{e^{1} e^{2} E^{1}}{2\left(1-v^{1^{2}}\right)} \\
& \frac{e^{1} E^{1}}{1-v^{1^{2}}} \\
& -\frac{13}{35}\left(\frac{e^{1}}{E^{1}}+\frac{e^{2}}{E^{2}}\right) \\
& 0 \quad 0 \\
& 0 \\
& 0 \\
& 0 \quad \frac{e^{2} E^{2}}{1-v^{2^{2}}} \\
& \frac{e^{2^{3}} E^{2}}{12\left(1-v^{2^{2}}\right)}
\end{aligned}
$$

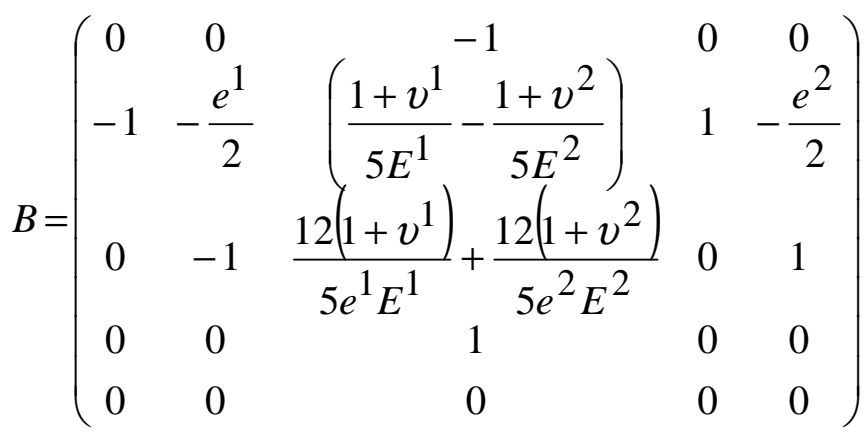




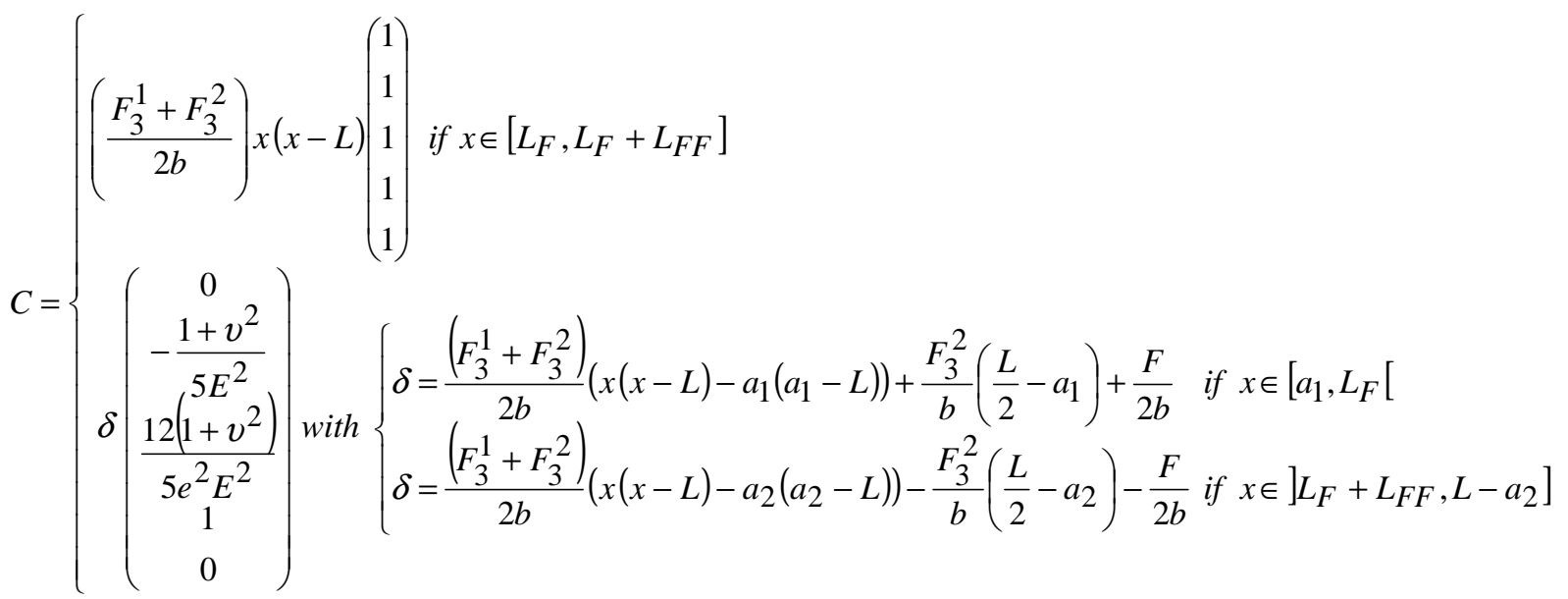

The shear stress $\tau_{1}^{1,2}(x)$ at the interface between layers 1 and 2, which is a function of the main unknowns of system (1), is obtained analytically from the M4-5n equation of interface shear behavior (5) between layers 1 and 2.

$$
\begin{aligned}
\tau_{1}^{1,2}(x)= & \frac{15 E^{1} E^{2}}{4\left(e^{1} E^{2}\left(1+v^{1}\right)+e^{2} E^{1}\left(1+v^{2}\right)\right)}\left(U_{1}^{2}(x)-U_{1}^{1}(x)\right) \\
& -\frac{15 E^{1} E^{2}}{4\left(e^{1} E^{2}\left(1+v^{1}\right)+e^{2} E^{1}\left(1+v^{2}\right)\right)}\left(\frac{e^{1}}{2} \Phi_{1}^{1}(x)+\frac{e^{2}}{2} \Phi_{1}^{2}(x)\right) \\
& \frac{3\left(1+v^{1}\right) E^{2}}{4\left(e^{1} E^{2}\left(1+v^{1}\right)+e^{2} E^{1}\left(1+v^{2}\right)\right)} Q_{1}^{1}(x)+\frac{3\left(1+v^{2}\right) E^{1}}{4\left(e^{1} E^{2}\left(1+v^{1}\right)+e^{2} E^{1}\left(1+v^{2}\right)\right)} Q_{1}^{2}(x)
\end{aligned}
$$

The normal stress $v^{1,2}(x)$ at the interface between layers 1 and 2, which is a function of the derivative of the main unknowns of system (1), is also obtained analytically by means of the M4-5n equilibrium equation of shear forces (6).

$$
v^{1,2}(x)=-Q_{1}^{1 '}(x)
$$

Moreover, all layer shear forces have been summed in order to verify the equilibrium condition set forth in (7).

$$
Q_{1}^{1}(x)+Q_{1}^{2}(x)= \begin{cases}\frac{\left(F_{3}^{1}+F_{3}^{2}\right)}{2 b}\left(x(x-L)-a_{1}\left(a_{1}-L\right)\right)+\frac{F_{3}^{2}}{b}\left(\frac{L}{2}-a_{1}\right)+\frac{F}{2 b} & \text { if } x \in\left[a_{1}, L_{F}[\right. \\ \frac{\left(F_{3}^{1}+F_{3}^{2}\right)}{2 b} x(x-L) & \text { if } x \in\left[L_{F}, L_{F F}\right] \\ \frac{\left(F_{3}^{1}+F_{3}^{2}\right)}{2 b}\left(x(x-L)-a_{2}\left(a_{2}-L\right)\right)-\frac{F_{3}^{2}}{b}\left(\frac{L}{2}-a_{2}\right)-\frac{F}{2 b} & \text { if } \left.x \in] L_{F F}, L-a_{2}\right]\end{cases}
$$


The expression of total energy $W_{e}$ of the the M4-5n is given in $[46,48]$. For a case of plane strain assumptions, its expression is written in the following equation (8)

$$
W_{e}=\sum_{i=1}^{2} \int_{\partial l}\left(w_{c}^{5 n^{i}}+w_{V}^{5 n^{i}}+w_{Q}^{5 n^{i}}\right) d x
$$

Where $w_{c}^{5 n^{i}}, w_{v}^{5 n^{i}}$ and $w_{Q}^{5 n^{i}}$ are M4-5n energies of the layer $\mathrm{i}$ of the plane stresses, the out of plane stresses and the shear stresses respectively. For each zone of the specimen (Fig. 1a), it is expressed analytically. For this elastic case, Hun's work [51] proved that the dead weight of each material is neglegible $\left(F_{3}^{i}=0\right)$. According to the figure $1 \mathrm{~b}$, and that an artificial delamination crack, denotes a, is happening on the right side of the specimen, it becomes (9).

$$
W_{e}(a)=\left[\begin{array}{l}
\left(\frac{\left(1-v^{2^{2}}\right)}{2} \frac{\left(a_{1}^{3}+(L-a)^{3}\right)}{e^{2^{3}}}+\frac{3\left(1+v^{2}\right)}{10} \frac{\left(a_{1}+(L-a)\right)}{e^{2}}\right] \frac{1}{E^{2}}\left(\frac{F}{b}\right)^{2} \\
+\frac{e^{1} E^{1}}{2\left(1-v^{1^{2}}\right)} \int_{a_{1}}^{L-a_{2}-a}\left[U_{1}^{1^{\prime}}\right]^{2} d x+\frac{e^{2} E^{2}}{2\left(1-v^{2^{2}}\right)} \int_{a_{1}}^{L-a_{2}-a}\left[U_{1}^{2^{\prime}}\right]^{2} d x+\frac{e^{1^{3}} E^{1}}{12\left(1-v^{1^{2}}\right)^{2}} \int_{a_{1}}^{L-a_{2}-a}\left[\Phi_{1}^{1^{\prime}}\right]^{2} d x \\
+\frac{e^{2^{3}} E^{2}}{12\left(1-v^{2^{2}}\right)^{2}} \int_{a_{1}}^{L-a_{2}-a}\left[\Phi_{1}^{2^{\prime}}\right]^{2} d x+\frac{13 e^{1}}{70 E^{1}} \int_{a_{1}}^{L-a_{2}-a}\left[Q_{1}^{1^{\prime}}\right]^{2} d x+\frac{e^{2}}{2 E^{2}} \int_{a_{1}}^{L-a_{2}-a}\left(\frac{\left(2 Q_{1}^{1^{\prime}}+Q_{1}^{2^{\prime}}\right)^{2}}{4}+\frac{17}{140}\left(Q_{1}^{2^{\prime}}\right)^{2}\right) d x \\
+\frac{6\left(1+v^{1}\right)}{5 e^{1} E^{1}} \int_{a_{1}}^{L-a_{2}-a}\left[Q_{1}^{1}\right]^{2} d x+\frac{6\left(1+v^{2}\right)}{5 e^{2} E^{2}} \int_{a_{1}}^{L-a_{2}-a}\left[Q_{1}^{2}\right]^{2} d x+\frac{e^{1} E^{1}}{5\left(1-v^{1^{2}}\right)} \int_{a_{1}}^{L-a_{2}-a}\left(\frac{\left(1+v^{1}\right)}{E^{1}} Q_{1}^{1}+\frac{\left(1+v^{2}\right)}{E^{2}} Q_{1}^{2}\right) U_{1}^{1^{\prime \prime}} d x \\
+\frac{2}{15}\left(\frac{e^{1} E^{1}}{1-v^{1^{2}}}\right)^{2}\left(\frac{e^{1}\left(1+v^{1}\right)}{E^{1}}+\frac{e^{2}\left(1+v^{2}\right)}{E^{2}}\right)_{a_{1}}^{L-a_{2}-a}\left[U_{1}^{1^{\prime \prime}}\right]^{2} d x
\end{array}\right]
$$

The interested reader should refer to [51] for a complete description of this equation (9).

Then classically, for a little variation of a, denotes " $\delta a$ ", it becomes possible to study, by means of the M45n [46, 50-51],the initial state of delamination along with the total strain energy release rate using equations (10) .

$$
G^{M 4-5 n}(a)=\frac{\partial W_{\text {ext }}(a)}{b \partial a}-\frac{\partial W_{e}(a)}{b \partial a} ; W_{\text {ext }}(a)=\frac{F}{2 b} U_{3}^{2}\left(\frac{L_{F}}{3}\right)+\frac{F}{2 b} U_{3}^{2}\left(\frac{2 L_{F F}}{3}\right)
$$

To interpret these test results, the delamination criteria based on energy considerations must involve the strain energy release rates relative to each fracture mode. The virtual crack closure technique (VCCT) offers 
a more useful and simpler approach to deriving these results with the help of the M4 formulation. For specific tension problems occurring with the composite materials, each M4 strain energy release rate relative to each fracture mode $\left(\mathrm{G}_{\mathrm{I}}, \mathrm{G}_{\mathrm{II}}, \mathrm{G}_{\mathrm{III}}\right)$ is expressed as a quadratic function of interfacial stresses at the crack tip [46, 49-50]. For the bending test conditions presented in the figure $1 \mathrm{~b}$, the analytical expressions of strain energy releases rates are given in the equation (11). Only $\mathrm{G}_{\mathrm{I}}$ is a pure quadratic function of the normal interface stress. $G_{I I}$ takes into account the combined terms containing the shear interface stress, shear force and load.

$$
\begin{aligned}
& G_{T}(a)=G_{I}(a)+G_{I I}(a) \\
& \text { with }\left\{\begin{aligned}
G_{I}(a)= & \frac{1}{2 b} \cdot \frac{13\left(e^{1} E^{2}+e^{2} E^{1}\right)}{G_{I I}(a)=}\left(v^{1,2}(a)\right)^{2} \\
2 b & \cdot \frac{3\left(e^{1}\left(1+E^{1} E^{2}\right) E^{2}+e^{2}\left(1+v^{2}\right) E^{1}\right)}{15 E^{1} E^{2}}\left(\tau^{1,2}(a)\right)^{2} \\
& -\frac{1}{2 b} \cdot\left(\frac{\left(1+v^{1}\right)}{5 E^{1}} Q_{1}^{1}(a)+\frac{\left(1+v^{2}\right)}{5 E^{2}} Q_{1}^{2}(a)\right) \cdot \tau^{1,2}(a)
\end{aligned}\right.
\end{aligned}
$$

\subsection{Validation of the numerical M4-5n results}

Boundary conditions of the central bi-layer zone where system (1) is solved are listed in Table 2 . The equations are numerically solved by applying a non-dimensional method along with the finite difference method, according to the Newmark scheme used in $[32,54]$ and implemented in the French open source software for numerical computations known as Scilab.

The solution to M4-5n equations has been successfully validated by comparison with $2 \mathrm{D}$ finite element simulations [35]. Althought the M4-5n equations can take into account the dead-weight contribution of each material as given in equation (4) and (7), as previously mentioned, Hun had proved that in elasticity it doesn't affect so much the results (that representents only $3.5 \%$ on the edge value of interface stresses) [51]. In the case of the specimen geometry described in Section 2.4 and materials tested under the displacementcontrolled condition laid out in Section 3.1, at edge point $x=a_{1}$ (Fig. 1), the figure 2 then illustrates the excellent level of convergence of the M4-5n interface normal and shear stress values $(5,6)$. Along the $x$-axis of the bi-layer zone II, for two different temperature conditions applied in the following tests, their intensities are well within the range of values given previously in the literature (see Table 1). Between the two external force points (i.e. B and C in Fig. 1), M4-5n interface stress intensities (Fig. 2), especially for normal stresses 
(Fig. 2b), are quite small and remain constant in comparison with the values from zones I and II near the edges. From these results, 1,200 elementary segments of the $x$ variable exceed the requirement for obtaining good numerical accuracy of interface stresses (around 99.98\%) at edge point $x=L-a_{2}$. Each simulation consumes no more than 2 seconds (in CPU time). Based on the interface stress field, this test should yield an interface fracture in mixed mode (i.e. modes I and II combined).

For the specimens tested and presented in this paper, depending on the interface stress intensity at the edge of an initially symmetrical specimen $\left(a_{1}=a_{2}=70 \mathrm{~mm}\right)$ (Fig. 3), $\mathrm{G}_{\mathrm{I}}$ is greater than $\mathrm{G}_{\mathrm{II}}$ (Fig. 3b). The evolution in energy release rate is given as a function of the normalized crack length a/LF where a varies along the $\mathrm{x}$ axle from $L-a_{2}$ to $L_{F}+L_{F F}$. The figure 3 a validates the simulation of energy release rate calculated by means of the VCCT method (11), in comparison with the total strain energy release rate obtained conventionally (10).

In addition, from the sign of the derivative of energy release with respect to the crack length, the crack expected to propagate along the interface is unstable before turning quite stable.

In the following section, the finite intensity of the M4-5n stresses at the edge location will subsequently be used in the parametric calculation in order to favor delamination over fracture by the bending mode. These stresses are primarily correlated with the tension at the bottom of layer 2, provided the modulus of layer 1 material is very small compared to the layer 2 modulus.

\subsection{Influence of specimen geometry and material characteristics on the stress field}

In this section, M4-5n simulations will be run on the global specimen geometry, which takes into account both the space constraints of the test and the heterogeneities of the material. This set-up yields a span length covering $420 \mathrm{~mm}$, a width of $120 \mathrm{~mm}$ and a $60-\mathrm{mm}$ thickness for each layer. Half of the 5-kN total load will be applied on each third of the span length. The loads and the and reaction forces are applied on the cement concrete material (layer 2) solely as a means of avoiding boundary condition problems during the test with the viscoelasticity and thermo-susceptibility of the bituminous material constituting layer 1 (Fig. 1). According to the NF EN 13108-1 Standard, the bituminous material tested in Section 3 is a conventional French bituminous mix obtained by using aggregate size $0 / 10$ and $5 \%$ of bitumen with $35 / 50$ penetration grade; it features a high air void content (9.59\%). The parameters of the Huet-Sayegh (HS) law [55-57] for 
the bituminous material selected herein (denoted BBSG 0/10) are listed in Table 3. The HS law depends on both frequency $\omega$ (with $e^{j \omega t}$ as the time variation) and temperature $\theta$ (12).

$$
E^{1}(\omega, \theta)=E_{0}+\frac{E_{\infty}-E_{0}}{1+\delta(j \omega \tau(\theta))^{-k}+(j \omega \tau(\theta))^{-h}}
$$

where $E_{\infty}$ is the instantaneous elastic modulus, $E_{0}$ is the static elastic modulus, $\mathrm{k}$ and $\mathrm{h}$ are the exponents of parabolic dampers $(1>h>k>0)$, and $\delta$ is a positive coefficient. In relation (12), $\tau(\theta)=\exp \left(A_{0}+A_{1} \theta+A_{2} \theta^{2}\right)$ is a function of temperature and involves three scalar parameters. The frequency value is correlated with loading rate conditions under some commonly used assumption [1]. For the displacement-controlled condition at a $0.7-\mathrm{mm} / \mathrm{min}$ loading rate, under the assumption described in Section 3.2 below, the equivalent modulus value of the bituminous material equals approximately 2,000 MPa at $20^{\circ} \mathrm{C}$ and $11,000 \mathrm{MPa}$ at $5^{\circ} \mathrm{C}$. The Poisson's ratio $v^{1}$ is assumed to be an elastic scalar.

The cement concrete material (denoted BC6) is made with a CEM I 52.5R cement (NF EN 206-1) and aggregate size 0/11. Its characteristics are given in Table 4; moreover, $R_{t}$ and $R_{c}$ classically denote the tensile and compressive strength values, respectively, of the material.

The following simulations have been performed for $1<\mathrm{E}^{2} / \mathrm{E}^{1}<30$ in a symmetric case: $\mathrm{a}_{1}=\mathrm{a}_{2}=70 \mathrm{~mm}$. Figure 4 indicates that as the Young's modulus ratio between the concrete material (layer 2) and the bituminous material (layer 1) decreases, the tensile stress intensity at the bottom of layer 2 shows a maximum at points A and D relative to points B and C. Intensities of the normal and the shear interface stress rise in absolute value terms at these points.

This M4-5n parametric analysis reveals that the tensile stress at the bottom of concrete layer 2 is in competition with interface stresses; this stress depends on the equivalent elastic value of the bituminous material modulus and hence on the test temperature. Depending on the tensile strength value of the cement concrete material, as well as interface properties and material heterogeneity, the specimen fracture mode during the test will also be influenced.

Due to the symmetry of a specimen's preliminary results, as presented in Hun et al. [35], delamination may occur first or simultaneously with failure in concrete on either side of the specimen. To force the delamination failure mode onto just one side of the specimen, asymmetric specimens will be numerically 
explored in the following discussion. The length $\mathrm{a}_{1}$ is set at $40 \mathrm{~mm}$ maximum with respect to the allowable distance from support to the edge of layer 1. For a lower value of the bituminous material modulus (i.e. $\mathrm{E}^{1}=$ 2,000 MPa), Figure 5 shows M4-5n simulations for various $a_{2}$ lengths. In Figure $5 a$, as length $a_{2}$ increases, the tensile stress intensity at the bottom of concrete layer 2 increases under loading point $C$ and the interface normal and shear stresses increase at the edge $\left(x=L-a_{2}\right)($ Fig. 5b). The parametric analysis confirms that the intensity of interface stresses at the edge $\left(x=L-a_{2}\right)$ increases from $20 \%$ to $60 \%$, in comparison with stresses on the other side when only the length $\mathrm{a}_{2}$ is increasing. For this test, a compromise must still be found between the tensile stress at the bottom of the cement concrete layer and both the shear and normal stresses at the edge of the interface.

\section{Experimental results on bi-material beam for composite pavement}

In [35,51], the modeling was first validated for tests on bi-layer specimen composed of aluminum as the first layer and PVC as the second. Debonding between these two materials was observed according to expectations. The elastic M4-5n simulation fits the elasticpart of experimental load-displacement curves. This section will present the initial experimental results obtained on a bi-material specimen for the composite pavement made with cement concrete and bituminous materials, as described above. The first subsection will discuss the experimental set-up, both types of interface characteristics (type I for UTW, type II by using a tack coat), and the initial visual observations on failure events during testing. The second subsection will examine the load displacement curves, as well as the load vs. strain measured at the bottom of the bituminous layer, focusing solely on delaminated specimens. Depending on material properties, a first interpretation of these results can then be provided by means of observations made on the experimental and some simulation curves.

\subsection{Description of test specimens and initial observations}

For the bituminous material and cement concrete materials described above in Tables 2 and 3, two types of interfaces have been tested. The type I interface pertains to a cement concrete overlay on bituminous material, known as the Ultra Thin Whitetopping (UTW) type. The type II interface corresponds to a bituminous material with the cement concrete material being bonded by means of a tack coat layer. 
For type I specimen, the cement concrete layer was cast directly onto the prefabricated bituminous slab. After one month, 3 composite slabs were sawed into 3 specimens (using the last number of the specimen numbering). For type II specimen, the cement concrete material was initially kept 28 days in a controlled chamber at $20^{\circ} \pm 2{ }^{\circ} \mathrm{C}$ and $50 \pm 10 \%$ of humidity rate before putting the tack coat. The porosity of this material is about $2.3 \%$. The surface of the cement concrete layer was cleaned by water blasting before placing the tack coat. The surface roughness of this material is similar to a smooth surface texture according to the study given in [20]. The tack coat is a French emulsion (C69 B4) used conventionally on top of the cement concrete layer. It is normally kept in a climatic chamber at $45^{\circ} \mathrm{C}$ prior to use. The emulsion, i.e. $0.4 \mathrm{~kg} / \mathrm{m}^{2}$ of residual binder, was applied to the concrete layer and left for 24 hours before being covered by the bituminous material layer. The bituminous material was then compacted by using the linear kneading compactor developed by LCPC. Lastly, the composite slabs were sawed into the same mandatory dimensions as the Type I specimen.

The common dimensions of each specimen are: $\mathrm{L}_{\text {total }}=480 \mathrm{~mm}$ for an $\mathrm{L}=420 \mathrm{~mm}$ dimension between supports, $\mathrm{e}^{1}=\mathrm{e}^{2}=60 \mathrm{~mm}$, and $\mathrm{a}_{2}=70 \mathrm{~mm}$. Two width values, as well as symmetrical and non-symmetrical specimens, have been tested. These geometries were designed by M4-5n calculations to simulate maximum stress intensity towards the interface edges. Under assumptions of elastic, homogeneous and isotropic materials and according to Figure 5, a higher value of $a_{2}$ compared to $a_{1}$ (Fig. 1) should favor delamination on the $\mathrm{a}_{2}$ side first. If such idea is proven and observed experimentally, then only one side needs to be instrumented in order to measure the crack propagation length. Tests were performed on a hydraulic press; during the test, the specimen temperature was controlled in a climatic aquarium chamber (Fig. 6a). The main advantage of this chamber is to offer the possibility to follow with visual or digital image inspection, every side and fracture zone of the specimen during the test. The test temperatures, loading rates, specific dimension and fracture observations for each specimen have been summarized in Table 5. To control and measure the imposed displacement, a linear variable differential transducer (LVDT) sensor was placed mid-height on the specimen section at the mid-span (Fig. 6b). Both types I and II specimens were delaminated according to this proposed test protocol (see Table 5, Figs. 6a and 9a).

For ambient temperature values around $20^{\circ} \mathrm{C}$, most type I specimens $(80 \%)$ were delaminated at the interface between layers either under load or controlled displacement conditions. Figure 7 shows that delamination occurs exactly at the interface location between layers even though the cement material has been flowing on 
top of the bituminous material, as is conventionally anticipated for a UTW structure. This finding implies that even if cement concrete fills the bituminous material voids and then assumed to strengthen the interface in the bituminous material just under the interface (Fig. 7a), the present four-point bending test is still able to delaminate the bi-material layers under the controlled conditions set forth in Table 5. On Figure 7b, it is nice to observe that this test produces an adhesive fracture for this Type I of interface. This test should yield valuable results for characterizing this type of interface.

For just a single specimen (Type I-PT-3-2), failure was observed in the central zone between the loading location points. In this case, the crack started in the middle of the specimen and at the bottom of the cement concrete layer. The central crack propagated vertically from the bottom of the concrete layer near the interface location into each part of the two materials (Fig. 8a). For an E2/E1 ratio value of around 20, Figure 4a demonstrates that a maximum tensile stress exists in this central part of the beam between loading locations B and C. In this zone, if a defect exists in the material, a crack may occur at the same spot. Moreover, for the two specimens I-PT-2.1 and I-PT-2.2, a bending failure in cement concrete occurred at $\mathrm{x}=\mathrm{a} 1$ (i.e. point $\mathrm{D}$ in Fig. $4 \mathrm{a})$. At a lower temperature $\left(4^{\circ} \mathrm{C}-\mathrm{E}^{2} / \mathrm{E}^{1}\right.$ ratio of approx. 3) for the type I-PT-1-2 specimen, failure was also located at the bottom of the concrete layer very close to point $\mathrm{D}$ of the edge zones (Fig. 4a). In addition to previous comments regarding the competition between tensile stress and interface stresses, these last failures are mainly facilitated by a strong bond between the layers and the irregular thickness of bituminous layers. For two specimens, the cement concrete layer thickness in the middle of the beam is indeed greater than at the edge (Fig. 8b). More precisely, the variation in thickness layer is due in particular to the method of compaction used for the bituminous material plates during the production phase. This finding suggests that considerable care must be taken during specimen fabrication. Consequently, the results on Type I-PT-3-2, I-PT-2.1 and I-PT-2.2 specimens have not been reported on the curves appearing in the following section (3.2). In addition, for few type I specimens and results stemming from the literature [7, 24, 34], some additional cracks at the bottom of the cement concrete under point B or C in Figure 4a may have occurred prior to delamination at location point A or D.

For specimen type II, much care was taken to introduce a regular thickness for all bituminous slabs during the compaction phase. Hence, for all Type II specimens, both the symmetric and non-symmetric specimens were ultimately delaminated at the interface between layers not only at ambient temperature (around $20^{\circ} \mathrm{C}$ ) but also, as depicted in Table 5, at lower temperatures (near $5^{\circ} \mathrm{C}$ ). As for Type I specimens, the exact 
location of debonding occurred between the 2 layers, as illustrated in Figure 9. Yet failure still happened twice as fast as for the previous type of interface (Table 5), which provides an interesting result when comparing these two types of interfaces. As for Figure $7 b$, the Figure $9 b$ gives the typical fracture area of the the broken interfaces. It is observed that for that Type II interface (with tack coat), as expected, it's a cohesion debonding. It has happened in the middle of the viscoelastic tack coat and makes the test much more complicated to interpret by an elastic model under no dead weight assumptions.

Furthermore, some observations have displayed the presence of a non-negligible effect from the bituminous layer self-weight on type II interfaces (i.e. with use of a tack coat). For this type II specimen, experimental results will likely be poorly modeled under the assumptions exposed in the first part of this paper regarding elasticity and the lack of self-weight effects. The test should be modified in order to deepen the level of understanding on this type of interface. In particular, this modification should be introduced in a completely opposite manner when loads originate from the bottom. Such a modification proved impossible with the hydraulic press used in this study.

\subsection{Experimental curve data}

In this section, only the curves associated with tests that ultimately produced delamination failure under controlled displacement conditions are reported for the two width values of bi-layers (i.e. $b=100$ and 120 $\mathrm{mm}$ ). The equivalent Young's modulus value of the bituminous material has been calculated through its HS law (12) at the test temperature. In an initial approximation for all tests conducted under the controlled displacement rate of $0.7 \mathrm{~mm} / \mathrm{min}$, the frequency is chosen as a function of test duration, which is to be determined by both experimental results (Table 5) and the M4-5n model with respect to the tensile stress limit within the cement concrete material (Fig. 5). This time $\left(\mathrm{T}=\mathrm{T}_{\mathrm{Rt}=3.5 \mathrm{MPa}}\right)$ corresponds to the maximum load $\mathrm{F}_{\mathrm{Rt}=3.5 \mathrm{MPa}}$, equal to $5 \mathrm{kN}$ and $7.2 \mathrm{kN}$ at high and low temperatures, respectively (see Figs. 10 and 12 ). From these loads, the test duration is determined by reviewing the experimental time-load result; it amounts to roughly $5.3 \mathrm{~s}$ for the two specimens tested at high and low temperature. In (12), the equivalent modulus of the bituminous layer is assumed to equal 2,000 MPa under ambient temperature conditions (around $20^{\circ} \mathrm{C}$ ), though its value rises to $11,000 \mathrm{MPa}$ at low temperature (approx. $5^{\circ} \mathrm{C}$ ). 
In the following curves, all results from Table 5 under controlled displacement conditions are displayed in the same graph. The load has been normalized by a coefficient that depends on the interface length and specimen width, both of which are parameters of the interface surface area.

First, for ambient temperature conditions, strong differences appear between the two types of interfaces, as observed in Figure 10. The static four-point bending test in static mode yields some highly repeatable results for Type I specimens, even though results are more widely dispersed for Type II. In addition, the average maximum load value for the Type I interface is about $50 \%$ higher than for the Type II interface. Except for the type I-PT-1-1 specimen, which raised certain difficulties with the displacement sensor, the global linear response of the Type I specimen can be simulated by an elastic M4-5n before the load reaches its maximum value and cracking occurs. This comment is also valid for strain measurements at the bottom of the middle part of the bituminous layer on the curves shown in Figure 11.

In order to experimentally determine if cracks occur before or after the maximum load value, first specimen type II-PT-1-3 and then type II-PT-2-2 (with fewer loadings) were subjected to several loadings before conducting the static test, and this was repeated until reaching the failure state. With respect to previous observations, it seems obvious that the dead weight of the bituminous material influences debonding of the viscoelastic tack coat. More specifically, this effect could explain why the elastic M4-5n does not fit very closely over the first part of these curves (Fig. 10). Such is especially true for type II-PT-1-3, which remains in the same position for quite a long time. The maximum load value is smaller here than for the other specimens (Figs. 10 and 11). To properly test this type of interface, which is not exactly the ultimate objective of this work, the present test would need to be improved. Nevertheless, it is important to point out that this test is able to provode some results for the two different types of interfaces.

Under the same controlled displacement rate $(0.7 \mathrm{~mm} / \mathrm{min})$ as for previous results, only one test on each interface has been performed at a lower temperature, i.e. set around $5^{\circ} \mathrm{C}$ (Fig. 12). Compared to results obtained at ambient temperature (see Fig. 10), we observe on Figure 12, that small visco-elactic effects exists in Type I specimen in regards to Type II ones. As a general indication for the type I specimen, the maximum force value of this test carried out at $5^{\circ} \mathrm{C}$ was of the same intensity as the value obtained for tests at $20^{\circ} \mathrm{C}$. The M4-5n curve perfectly fits the experimental displacement and strain result before failure occurs in the cement concrete layer. For the type I-PT-1-2 specimen, no interface debonding was observed, as opposed to the type II-PT-1-1 specimen failure mode (Table 5). Once again, for the type II specimen, before failure can 
occur at the bottom of the cement concrete layer, dead weight effects of the bituminous layer on the viscoelastic tack coat may complicate this analysis. The linear portion of the curve is in fact shorter than the elastic simulation performed with M4-5n before the presumed cement concrete failure (Fig. 12b). A much greater number of tests must naturally be completed in order to confirm these results.

According to the M4-5n simulations illustrated in Figure $4 \mathrm{~b}$ however and in comparison with observations and experimental results for ambient temperature (i.e. around $20^{\circ} \mathrm{C}$ ), each type of interface appears at $5^{\circ} \mathrm{C}$ to resist higher values of both normal and shear interface stresses at point D. In considering that these M4-5n interface stresses might provide a good indicator of delamination criteria when very few visco-elastic effect exists (as for the Type I specimen), it could then be interpreted that the behavior of the composite interface between the cement concrete and the bituminous material should be considered as thermosusceptible.

\subsection{Discussion}

M4-5n simulations (Fig. 4), in correlation with cement concrete material characteristics (Table 3) and initial experimental observations (Table 5, Fig. 8a), indicate that a competition exists between tensile stress at the bottom of the cement concrete layer and interface normal and shear stresses. As opposed to tests conducted on ALU/PVC specimens, the experimental determination of strain energy release rate by means of the classical compliance method [58] and crack mouth opening measurements seems more complicated to apply to the bi-layer specimen made from cement concrete and bituminous materials [52].

The competition between stresses described above can be summarized and discussed briefly at certain points on the load displacement curves using simple elastic calculus. Some values will be given below. Previous experimental curves of load displacements (Figs. 10 and 12) have indicated three distinct zones: A, B and C. These zones are illustrated in Figure 13 for specimen I-PT-1-3 and II-PT-2-1 only. Cases 1 through 4 illustrate the finite element (FEM) simulations.

Zone A corresponds to the linear part of the curves, before either the possible failure at the bottom of the cement concrete layer or the viscoelastic effect of the bituminous material. In this zone, M4-5n curves generally fit all tests of the type I specimen with its average material modulus values for each temperature (Figs. 10-12). For type II specimens, focusing in particular on the load versus strain curves at the bottom of the bituminous layer, the M4-5n curves do not all fit the experimental curves (Figs. 11 and 12b). As explained in the previous section, this finding is probably due to the dead-weight effects of the bituminous 
layer on the viscoelastic tack coat. For the type II interface, on the contrary to the type I interface, this effect must therefore be taken into account in the model or else the test schematic diagram needs to be modified. In zone B, cracks may occur anywhere (either in the cement concrete material or on the interface location). The end of zone B is chosen to be associated with the complete debonding case, without any cracks appearing at the bottom of the concrete layer (Fig. 13). This calculation has been performed according to classical fourpoint bending theory (RDM: strength of materials) on the cement concrete beam only. The curves at ambient temperature match the maximum load value (Fig. 13). At lower temperatures, this value corresponds to a point on the curve just after the maximum load value (Fig. 12). Regardless of the case, zone B is small and delamination cannot by itself describe the entire curve. As a matter of fact, even if viscoelastic effects of the bituminous layer are taken into consideration, three failure possibilities exist in zone B: only one crack appears at the bottom of the cement concrete layer (case 1); total delamination of just one side of the beam (case 2) until point B or C (Fig. 1); or a small vertical crack at the bottom of the cement concrete layer, coupled with a total delamination of one edge (case 3), as can be observed as well in Figure 9a for a II-PT-21 specimen. Under these assumptions, zone $\mathrm{C}$, where both cracks at the bottom of layer 2 and delamination are sure to be found, should then mainly correspond to the propagation zone for the crack in the cement concrete until the end of the test (case 4).

In subsequent studies, these investigations will need to be improved and validated by further details along with both the introduction, in the M4-5n simulation, of vertical failure in the cement concrete layer and the use of a digital image correlation technique. To complete this first effort and provide some indicators, if no cracks occur at the bottom of the cement concrete layer before delamination (i.e. case 2), then additional values of the M4-5n interface stresses at point D (or A) in Figure 1 and the strain energy release rate have been listed in Table 6 . These values have been calculated for two force intensities $\left(\mathrm{F}_{\mathrm{t}=5.3 \mathrm{~s}}\right.$ : end of zone $\mathrm{A}$; and $\mathrm{F}_{\max }$ : end of zone $\mathrm{B}$ ) for tests carried out at ambient temperature. If debonding initiates from the edge of the beam only, then the critical experimental interface stresses or $\mathrm{G}$ intensities should lie between these values, which are in the range of values given in the literature (Table 1) [27].

In subsequent studies, these values will need to be complemented by interface normal and shear stress values near the vertical concrete crack (case 1 of Fig. 13) so as to precisely determine which intensity is higher.

\section{Conclusions}


In order to deep the knowledge about the characterization of interface bond, this aim of this article is to give some answers to the three questions given in the introduction and not to examine the debonding interface problems with great details on interface characteristics in a well-known test and not to propose a practical test for being standardized. The term "mechanical analysis" is used to indicate that this experimental and modelling work is voluntary not performed at a micro scale level (as for instance at the level of cohesive zone behind the crack). This paper doesn't pretend either at all to do similar statistical investigations to compare results of different tests such as those done in [59]. Actually, the work presented in this paper gives some answers to the three points of the objectives given in the introduction. A 4PB test on bi-layer structures has been analyzed using a specific elastic model. The influence of geometry on the delamination phenomenon in specimens has been studied. First, one shows that the elastic model used is really efficient to design the geometry of the specimen. The elastic solutions compute into Scilab are obtained very quickly which allows making different parametric studies. As expected, this test shows significant rupture at the interface in mixed mode (modes I and II combined) conditions, though mode I should be recognized as the main failure mode. The VCCT method helps separate the two modes from the strain energy release rate. These initial results on various types of interfaces tested under controlled static conditions have been presented. Actually, in a pavement, a concrete layer can be covered by a bituminous surface course and a tack coat is used to ensure the bond between the layers. As second case, a bituminous layer can be covered by a cement concrete without using a tack coat. The two possibilities of construction during laying process give two kinds of interface. In each case, the interface bond needs more investigation in laboratory and one proposes in this paper some tests to evaluate the interface bond meanly at ambient temperature. These preliminary experiments have been done to check the capability of the four-point bending test to distinguish between the two types of interface. In the same way, some tests have been also conducted at lower temperatures. Different failure mechanisms, primarily including delamination, have been observed. This 4point bending test has been able to highlight differences between interface types. Due to the strong selfweight effect of the bituminous layer for interface specimen type II (bituminous layer placed on the cement concrete layer by means of a tack coat film), this test needs to be modified in order to improve the study of this type of interface. In considering the deflection behavior of specimens, both experimental and analytical results have been compared. Interface normal and shear stress intensities between layers at the edge of the specimen, as output from the model, are in the range of values found in the literature for type I interfaces 
(UTW type). For this type of interface (Type II), the four point bending test investigated here is very interesting for its capability to debond such a bi-material specimen. We conclude that the statistical work (with different temperatures/loading conditions, roughness of material, moisture or water effect ...) can be planned. As for composite materials [45, 48-49], delamination can be predicted using the quadratic failure criterion in terms of these M4 interface stresses. For the pair of materials tested however, it would appear that strong competition exists between a crack at the bottom of the cement layer and a debonding crack, which further complicates crack length measurements by means of classical techniques.

In looking to future studies, additional simulations for the purpose of introducing, under loading points of the specimen, an initial crack at the bottom of the concrete layer into the model should help determine the exact cracking and debonding mechanisms of these specimens. Through the use of image analysis techniques, this information should be also provided and the parameters of mixed mode criteria should also be indicated.

\section{Acknowledgments}

The authors are grateful to Jean-Noël Velien and the entire LRPC-Angers Regional Civil Engineering Laboratory for specimen production and to Jean-Philippe Terrier for his technical assistance in the use of the hydraulic press.

\section{References}

[1] Pouteau B. Durabilité mécanique du collage blanc sur noir dans les chaussées. PhD thesis. Ecole Centrale de Nantes, France 2004 [In French].

[2] Pouteau B, Chabot A, De Larrard F, Balay JM. Mécanique des chaussées Béton sur grave-bitume, étude de la tenue du collage entre béton et enrobé sur chaussée expérimentale (1re partie). Revue Générale des Routes et des Aérodromes 2006 ; (847): 85- 90.

[3] Chabot A, Pouteau B, Balay JM, De Larrard F. FABAC Accelerated Loading Test of Bond between Cement Overlay and asphlat layers. In: Al Qadi A, Scarpas T., Loizos A., editors. Pavement cracking, London: CRC Press/Balkema. Proceedings of the Sixth International RILEM Conference on Cracking in Pavements, Chicago, US, June 16th-18th 2008; 13-23 [ISBN 13: 978-0-415-47575-4, Hbk + CD-ROM].

[4] Perez S, Balay JM, Tamagny P, Petit C. Accelerated Pavement Testing and Modeling of Reflective Cracking in Pavements. Journal Engineering Failure Analysis 2007; 14 (8):1526-1537. 
[5] Charalambides PG, Lund J, Evans AG, McMeeking RM. A test specimen for determining the fracture resistance of bi-material interfaces. Journal of Applied Mechanics 1989; 56, 77-82.

[6] Reeder JR, Crews JH. Mixed-mode bending method for delamination testing. American Institute of Aeronautics and Astronautics Journal 1990; 28 (7):1270-1276.

[7] Wanga B, Siegmund T. A modified 4-point bend delamination test. Microelectronic Engineering 2008; 85 (2): $477-485$.

[8] Brown SF, Brunton JM. The influence of bonding between bituminous layers. Highways and Transportation 1984; 31(5):16-7.

[9] Vecoven J.H. Méthode d'étude des systèmes limitant la remontée de fissures dans les chaussées. In: Rigo JM, Degeimbre R, editors. Proceedings of the International RILEM Conference on Reflective Cracking in Pavements - Assessment and Control, Liège, Belgium, March 8th - 10th 1989 ; 57-62.

[10] Tschegg KE, Kroyer G, Tan DM, Stanzl-Tschegg SE, Litzka J. Investigation of bonding between asphalt layers on road construction. Journal of Transportation Engineering - ASCE 1995; 309-317.

[11] Francken L, Vanelstraete A. On the thermo rheological properties of interface systems. Rigo JM, Degeimbre R, Francken L, editors. Proceedings of the 2th International RILEM Conference on Reflective Cracking in Pavements - State of the Art and Design Recommendations, Liège, Belgium, March 10th - 12th 1993; 206-219.

[12] Francken L, Beuving E, Molenaar AAA, editors. Proceedings of the 3rd RILEM Conference Reflecting Cracking in Pavements - Design and Performance of overlay systems, E\&FN SPON, Maastricht, The Netherlands, Oct. 2th-4 th 1996.

[13] de Bondt A. Anti-reflective cracking design of (reinforced) asphalt overlays. PhD thesis, Delft University of Technology, The Netherlands; 1999.

[14] Tschegg EK, Jamek M, Lugmayr R. Fatigue crack growth in asphalt and asphalt-interfaces. Engineering Fracture Mechanics 2011; 78: 1044-1054.

[15] Canestrari F, Ferrotti G, Partl MN, Santagata E. Advanced testing and characterization of interlayer shear resistance. Journal of Transportation Research Board 2005; 1929:69-78.

[16] Diakhaté M, Phelipot A, Millien A, Petit C. Shear fatigue behaviour of tack coats in pavements. Road Materials and Pavement Design International Journal 2006; 7 (2):201-22. 
[17] Piber H, Canestrari F, Ferrotti G, Lu X, Millien A, Partl MN. RILEM interlaboratory test on interlayer bonding of asphalt pavements. In Loizos A, Partl MN, Scarpas T, Al-Qadi I, editors. Proceeding of the 7th international RILEM symposium on advanced testing and characterization of bituminous material, Rhodes, Greece, 27-29 May 2009; 2:1191-1200.

[18] Raab C, Partl MN. Interlayer bonding of binder, base and subbase layers of asphalt pavements: Longterm performance. Construction and Building Materials 2009; 23 : 2926-2931.

[19] Collop AC, Sutanto MH, Airey GD, Richard C. E. Development of an automatic torque test to measure the shear bond strength between asphalt. Construction and Building Materials 2011; 25: 623-629.

[20] Al-Qadi, I., Carpenter, S., , Leng, Z., Ozer, H., and Trepanier, J. (2008). Tack coat optimization for hma overlays : Laboratory testing. Technical Report FHWA-ICT-08-023, Illinois Center for Transportation.

[21] Teng JG, Smith ST, Yaoa J, Chen JF. Intermediate crack-induced debonding in RC beams and slabs. Construction and Building Materials 2003; 17:447-462.

[22] Turatsinze A, Granju JL, Sabathier V, Farhat H. Durability of bonded cement-based overlays: effects of metal fibre reinforcement. Materials and structures 2005; 38 (3): 321-327.

[23] Perez F, Bissonnette B, Gagné R. Parameters affecting the debonding risk of bonded overlays used on reinforced concrete slab subjected to flexural loading. Materials and Structures 2009; 42 (5): 645-662.

[24] Pan J, Leung CKY, Luo M. Effect of multiple secondary cracks on FRP debonding from the substrate of reinforced concrete beams. Construction and Building Materials 2010; 24: 2507-2516

[25] Bissonnette B, Courard L, Fowler DW, Granju JL, editors. Bonded Cement-Based Material Overlays for the Repair, the Lining or the Strengthening of Slabs or Pavements. State-of-the-Art Report of the RILEM Technical Committee 193-RLS Series, Publisher Springer Netherlands; 2011; 3 [ISBN 978-94007-1238-6 (Print) 978-94-007-1239-3 (Online)].

[26] Petersson Ö, Silfwerbrand J. Thin concrete overlays on old asphalt roads. In the proceedings of the 5th International conference on Concrete pavement design and rehabilitation, Purdue University, USA, April 20th-22th 1993; 2: 241-246.

[27] Mack JW, Wu CL, Tarr SM, Refaï T. Model development and interim design procedure guidelines for ultra-thin whitetopping pavements. In the proceedings of the 6th International conference on Concrete pavement design and rehabilitation, Indianapolis, USA, November 1997; 1: 231-254. 
[28] Tschegg EK, Macht J, Jamek M, Stegenberger J. Mechanical and Fracture-Mechanical Properties of Asphalt-Concrete Interfaces. ACI Materials Journal 2007;104 (5): 474-480.

[29] Delcourt C, Jasenski A. First application of a concrete overlay on a bitumen-paved motorway in Belgium. In the Proceedings of the 7th International Symposium on Concrete Roads 1994; 2, 3:15-20.

[30] Silfwerbrand J. Whitetoppings. In the Proceedings of the 8th International Symposium on Concrete Roads 1998; Theme IV: 139-148.

[31] Rasmussen RO, Rozycki DK. Thin and Ultra Thin Whitetopping - A synthesis of highway practice, NCHRP Synthesis 338, Transportation Research Board 2004.

[32] Tran QD. Modèle simplifié pour les chaussées fissurées multicouches. PhD Thesis. Ecole Nationale des Ponts et Chaussées, France ; 2004 [In French].

[33] Chabot A, Tran QD, Ehrlacher A. A modeling to understand where a vertical crack can propagate in pavements. In Loizos A, Scarpas T, Al-Qadi I, editors. Proceedings of the International Conference on Advanced Characterization of Pavement and Soil Engineering Materials, Athens, Greece. In Taylor \& Francis Group, June $20^{\text {th }}-22^{\text {th }} 2007 ; 1: 431-440$ [ISBN 978-0-415-44882-6].

[34] Achintha M, Burgoyne CJ. Fracture mechanics of plate debonding: Validation against experiment. Construction and Building Materials 2011; 25: 2961-2971.

[35] Hun M, Chabot A, Hammoum F,. Analyses mécaniques d'une structure bi-couches délaminantes par flexion 4 points. 20ème Congrès Français de Mécanique (CFM2011), Besançon, France, 28 Août - 2 septembre 2011; [http://documents.irevues.inist.fr/handle/2042/45818, In French].

[36] Williams ML. The stress around a fault or crack in dissimilar media. Bulletin of the Seismological Society of America 1959; 49:199-204.

[37] England AH. A crack between dissimilar media. Journal of Applied Mechanics 1965; 32:400-402.

[38] Dundurs J. Edge-bonded dissimilar orthogonal elastic wedges under normal and shear loading. Transactions of the ASME, Journal of Applied Mechanics 1969; 650-652.

[39] Cook TS, Erdogan F. Stresses in bonded materials with a crack perpendicular to the interface, International Journal of Engineering Science 1972; 10: 677-697.

[40] Comninou M. The interface crack. Journal of Applied Mechanics 1977; 44: 631-636.

[41] Sun CT, Jih CJ. On strain energy release rates for interfacial cracks in bi-material media. Engineering Fracture Mechanics 1987; 28 (1):13-20. 
[42] He MY, Hutchinson JW. Crack deflection at an interface between dissimilar elastic materials. International Journal of solides and structures 1989; 25 (9):1053-1067.

[43] Raju IS, Crews JH, Aminpour MA. Convergence of strain energy release rate components for edgedelaminated composite laminates. Engineering Fracture Mechanics 1988; 30:383-396.

[44] Naciri T, Ehrlacher A, Chabot A. Interlaminar Stress Analysis with a new Multiparticle Modelisation of Multilayered Materials (M4). Composites Sciences and Technology 1998, 58 (3): 337-343.

[45]Chabot A, Ehrlacher A. Modèles Multiparticulaires des Matériaux Multicouches M4_5n et M4_(2n+1) M pour l'étude des effets de bord. Comptes-rendus aux 11ème Journées Nationales sur les Composites (JNC11), Arcachon, France, 18-20 nov. 1998 ; 3 :1389-1397 [http://hal.archives-ouvertes.fr/hal00325238/en/].

[46] Chabot A. Analyse des efforts à l'interface entre les couches des matériaux composites à l'aide de Modélisations Multiparticulaires des Matériaux Multicouches (M4). PhD thesis. Ecole Nationale des Ponts et Chaussées, France, 1997 [http://tel.archives-ouvertes.fr/tel-00197853/en/ in French)].

[47] Reissner E. On a Variational Theorem in Elasticity. Journal of Mathematical Physics 1950 ; 29: 90-95.

[48] Carreira RP, Caron JF, Diaz Diaz A. Model of multilayered materials for interface stresses estimation and validation by finite element calculations. Mechanics of Materials 2002; $34: 217-230$.

[49] Chabot A, Cantournet S, Ehrlacher A. Analyse de taux de restitution d'énergie par un modèle simplifié pour un quadricouche en traction fissuré à l'interface entre 2 couches. Comptes-rendus aux 12ème Journées Nationales sur les Composites (JNC12), ENS de Cachan, France, 15-17 novembre 2000 ; 2 : 775-784 [ISBN 2-9515965-0-2].

[50] Caron J F, Diaz Diaz A, Carreira RP, Chabot A, Ehrlacher A. Multi-particle modeling for the prediction of delamination in multi-layered materials. Composites Sciences and Technology 2006; 66 (6): 755-765.

[51] Hun M. Influence de l'eau sur le décollement d'une interface par flexion d'un bisouche de chaussée urbaine. PhD thesis. Ecole Centrale de Nantes, France, 2012 [in French].

[52] Hun M, Chabot A, Hammoum F. A four point bending test fort the bonding evaluation of composite pavement. In Proceedings of the 7th International RILEM Conference Cracking in Pavements, Delft, the Netherlands, June 20-22 2012.

[53] Hutchinson JW, Suo Z. Mixed mode cracking in layered materials. Adv. Appl. Mech. 1992; 29: 63-191. 
[54] Chabot A, Tran QD, Ehrlacher A. A simplified modeling for cracked pavements - Modèle simplifié pour le calcul des chaussées. Bulletin des Laboratoires des Ponts et chaussées 2005 ; (258-259) : 105-120 [http://www.lcpc.fr/en/sources/blpc/index.php].

[55] Huet C. Etude par une méthode d'impédance du comportement viscoélastique des matériaux hydrocarbonés. PhD Thesis. Faculty of Sciences of Université de Paris, France, 1963 [in French]

[56] Sayegh G. Contribution à l'étude des propriétés viscoélastiques des bitumes purs et des bétons bitumineux. PhD Thesis. Faculty of Sciences of Université de Paris, France, 1965 [in French].

[57] Huet C. Coupled size and boundary-condition effects in viscoelastic heterogeneous and composite bodies. Mechanics of Materials 1999; 31: 787-829.

[58] Berry JP. Determination of fracture surface energies by the cleavage technique. J. Appl. Phys. 1963; 3462.

[59] Santagata Felice A., Ferrotti Gilda, Partl Manfred N., Canestrari Francesco. Statistical investigation of two different interlayer shear test methods. Materials and Structures, 2009, 42 (6): 705-714 


\section{List of Tables}

Table 1: Illustration of some mechanical strength data between a cement concrete overlay on a bituminous material ( $v$ and $\tau$ are the normal and shear interface stresses respectively)

Table 2: Numerical boundary conditions of the bilayer modelled (zone II of Figure 1)

Table 3: Bituminous material characteristics with high level of void content (IFSTTAR A476)

Table 4: Cement material characteristics (IFSTTAR -A476)

Table 5: Dimension of bi-layer specimens, test conditions and visual observations

Table 6: Interface stress intensity and strain energy release rate results for ambient temperature (around $20^{\circ} \mathrm{C}$ ) 
Table 2: Illustration of some mechanical strength data between a cement concrete overlay on a bituminous material ( $v$ and $\tau$ are the normal and shear interface stresses respectively)

\section{$\square$ : Bituminous material $\square$ : Cement concrete}

\begin{tabular}{l}
\hline Test \\
\hline Direct tensile test (Mode I) \\
\hline
\end{tabular}

Wedge splitting test (Mode I)

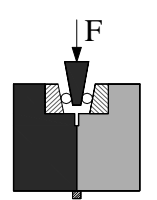

- Cores from a bonded (milled surface) thin cement concrete pavement after 4 months of traffic [27] : $v=2,6$ à 3,2MPa (test at $\left.-10^{\circ} \mathrm{C}\right), v=1.3$ à $1.6 \mathrm{MPa}$ (test at $\left.10^{\circ} \mathrm{C}\right), v=0.7 \mathrm{MPa}$ $70 \mathrm{~J} / \mathrm{m} 2<\mathrm{G}<100 \mathrm{~J} / \mathrm{m} 2\left(\right.$ test at $22^{\circ} \mathrm{C}$ )

Shear test (Mode II)

- Cores from a concrete slab over a bituminous material base [28]: $\tau=0.8 \mathrm{MPa}$

- Cores from a bonded (milled surface) thin cement concrete pavement after 6 months of

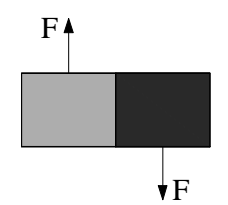
traffic [26]: $\tau=0.7 \mathrm{MPa}$

- Cores from a bonded (milled surface) thin cement concrete pavement [29]: $\tau=0.4 \mathrm{MPa}$ Cores from a bonded (milled surface) thin cement concrete pavement after 1 year of traffic [30]: $\tau=0.5$ à $0.7 \mathrm{MPa}$

EPCF test (Mixed mode)

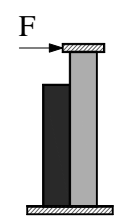

Specimens from a laboratory test without any interface treatment [1] :

$\nu=0.6$ to $1 \mathrm{MPa}, \tau=0.3$ to $0.8 \mathrm{MPa}$ (static test at $0^{\circ} \mathrm{C}-0.11 \mathrm{~mm} / \mathrm{min}$ )

$v<1.8 \mathrm{MPa}, \tau<0.8 \mathrm{MPa}$ (fatigue test at $0^{\circ} \mathrm{C}$ and $10 \mathrm{~Hz}$ ) 
Table 2: Numerical boundary conditions of the bilayer modelled (zone II of Figure 1)

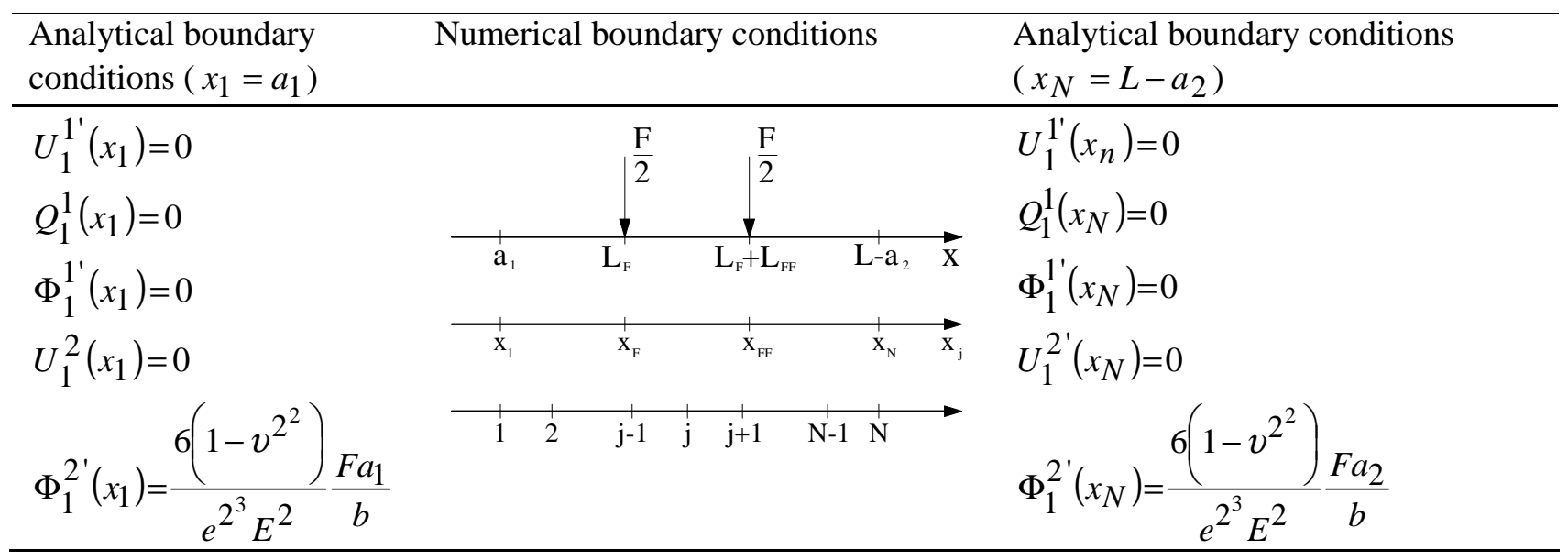

Table 3: Bituminous material characteristics with high level of void content (IFSTTAR A476)

\begin{tabular}{llllllllll}
\hline Bituminous material & $\mathrm{E}_{0}$ & $\mathrm{E}_{\text {inf }}$ & $\delta$ & $\mathrm{k}$ & $\mathrm{h}$ & $\mathrm{A}_{0}(\mathrm{~s})$ & $\mathrm{A}_{1}\left(\mathrm{~s}{ }^{\circ} \mathrm{C}-1\right)$ & $\mathrm{A}_{2}\left(\mathrm{~s}{ }^{\circ} \mathrm{C}-2\right)$ & $v^{1}$ \\
& $(\mathrm{MPa})$ & $(\mathrm{MPa})$ & & & & & & & \\
\hline BBSG 0-10 & 25 & 27535 & 2.38 & 0.23 & 0.69 & 3.8251 & -0.39086 & 0.0016067 & 0.35 \\
\hline
\end{tabular}

Table 4: Cement material characteristics (IFSTTAR -A476)

\begin{tabular}{llllllll}
\hline Cement Concrete & Cement type & Granular size & Air void (\%) & $\mathrm{E}^{2}(\mathrm{MPa})$ & $v$ & $\mathrm{R}_{\mathrm{t}}(\mathrm{MPa})$ & $\mathrm{R}_{\mathrm{c}}(\mathrm{MPa})$ \\
\cline { 2 - 7 } BC6 & CEM I 52.5R & $0 / 11$ & 2.57 & 34878 & 0.25 & 3.46 & 47.67 \\
\hline
\end{tabular}


Table 5: Dimension of bi-layer specimens, test conditions and visual observations

\begin{tabular}{|c|c|c|c|c|c|c|}
\hline $\begin{array}{l}\text { Specimen } \\
\text { name }\end{array}$ & $\begin{array}{l}\mathrm{b} / \mathrm{a}_{1} \\
(\mathrm{~mm})\end{array}$ & $\begin{array}{l}\text { Controlled } \\
\text { conditions }\end{array}$ & $\begin{array}{l}\mathrm{T} \\
\left({ }^{\circ} \mathrm{C}\right) \\
\end{array}$ & $\begin{array}{l}\mathrm{F}_{\max } \\
(\mathrm{N})\end{array}$ & $\begin{array}{l}\mathrm{t}_{\mathrm{Fmax}} \\
(\mathrm{s})\end{array}$ & Visual observations \\
\hline I-PT-1-1 & $120 / 70$ & $0.7 \mathrm{~mm} / \mathrm{min}$ & 21.0 & 12150 & 17.5 & Interface debonding \\
\hline I-PT-1-2 & $120 / 70$ & $0.7 \mathrm{~mm} / \mathrm{min}$ & 4.0 & 12190 & 10.5 & Bending fracture (Edge of layer 2) \\
\hline I-PT-1-3 & $100 / 70$ & $0.7 \mathrm{~mm} / \mathrm{min}$ & 20.0 & 9760 & 28.0 & Interface debonding \\
\hline I-PT-2-1 & $120 / 70$ & $0.7 \mathrm{~mm} / \mathrm{min}$ & 20.0 & 11900 & 20.7 & Bending fracture (Edge of layer 2) \\
\hline I-PT-2-2 & $120 / 70$ & $500 \mathrm{~N} / \mathrm{s}$ & 20.0 & 8465 & 22.5 & Bending fracture (Edge of layer 2) \\
\hline I-PT-2-3 & $120 / 70$ & $100 \mathrm{~N} / \mathrm{s}$ & 23.0 & - & 73.3 & Interface debonding \\
\hline I-PT-3-1 & $120 / 70$ & $0.7 \mathrm{~mm} / \mathrm{min}$ & 20.0 & 11560 & 20.0 & $\begin{array}{l}\text { Cracking in cement concrete layer then } \\
\text { interface debonding }\end{array}$ \\
\hline I-PT-3-2 & $120 / 70$ & $0.7 \mathrm{~mm} / \mathrm{min}$ & 21.0 & 11090 & 18.0 & Bending fracture (middle of layers) \\
\hline I-PT-3-3 & $100 / 70$ & $0.7 \mathrm{~mm} / \mathrm{min}$ & 22.0 & 8850 & 25.0 & Interface debonding \\
\hline II-PT-1-1 & $120 / 70$ & $0.7 \mathrm{~mm} / \mathrm{min}$ & 6.0 & 10780 & 13.4 & Interface debonding \\
\hline II-PT-1-2 & $120 / 70$ & $0.7 \mathrm{~mm} / \mathrm{min}$ & 20.0 & 6800 & 13.9 & $\begin{array}{l}\text { Cracking in cement concrete layer then } \\
\text { interface debonding }\end{array}$ \\
\hline II-PT-1-3 & $100 / 70$ & $0.7 \mathrm{~mm} / \mathrm{min}$ & 20.5 & 4300 & 12.5 & $\begin{array}{l}\text { Cracking in cement concrete layer then } \\
\text { interface debonding }\end{array}$ \\
\hline II-PT-2-1 & $120 / 40$ & $0.7 \mathrm{~mm} / \mathrm{min}$ & 22.0 & 5600 & 11.0 & $\begin{array}{l}\text { Cracking in cement concrete layer then } \\
\text { interface debonding }\end{array}$ \\
\hline II-PT-2-2 & $120 / 40$ & $0.7 \mathrm{~mm} / \mathrm{min}$ & 20.0 & 6000 & 14.0 & $\begin{array}{l}\text { Cracking in cement concrete layer then } \\
\text { interface debonding }\end{array}$ \\
\hline II-PT-2-3 & $100 / 40$ & $0.7 \mathrm{~mm} / \mathrm{min}$ & 20.5 & 5200 & 9.7 & $\begin{array}{l}\text { Cracking in cement concrete layer then } \\
\text { interface debonding }\end{array}$ \\
\hline
\end{tabular}


Table 6: Interface stress intensity and strain energy release rate results for ambient temperature (around $20^{\circ} \mathrm{C}$ )

\begin{tabular}{|c|c|c|c|c|c|c|c|c|}
\hline \multirow{3}{*}{$\begin{array}{l}\text { Specimen } \\
\text { type }\end{array}$} & $\begin{array}{l}\text { Average } \\
\text { maximum }\end{array}$ & \multirow{3}{*}{$\begin{array}{l}\mathrm{F}_{\mathrm{t}=5.3 \mathrm{~s}} \\
(\mathrm{~N})\end{array}$} & \multirow{3}{*}{$\begin{array}{l}\tau_{F_{M a x}}^{1,2}\left(L-a_{2}\right) \\
(\mathrm{MPa})\end{array}$} & \multirow{3}{*}{$\begin{array}{l}\tau_{F t=5.3 s}^{1,2}\left(L-a_{2}\right) \\
(\mathrm{MPa})\end{array}$} & \multirow{3}{*}{$\begin{array}{l}v_{F_{M a x}}^{1,2}\left(L-a_{2}\right) \\
(\mathrm{MPa})\end{array}$} & \multirow{3}{*}{$\begin{array}{l}v_{F_{F t=5.3 s}^{1,2}}\left(L-a_{2}\right) \\
(\mathrm{MPa})\end{array}$} & \multicolumn{2}{|c|}{ length of $2 \mathrm{~mm}$} \\
\hline & $\operatorname{load}(\mathrm{N})$ & & & & & & \multicolumn{2}{|c|}{ Model } \\
\hline & & & & & & & $\mathrm{G}_{\mathrm{Fmax}}$ & $\mathrm{G}_{\mathrm{Ft}=5.3 \mathrm{~s}}$ \\
\hline Type I & $9760-12150$ & 5000 & $0.42-0.48$ & 0.20 & $1.18-1.34$ & 0.55 & $100-112$ & $44-80$ \\
\hline
\end{tabular}




\section{List of Figures}

Figure 1. (a) Four-point bending test on bilayer materials (b) anti-symmetrical debonding case Figure 2. Interface M4-5n stresses and numerical convergence of calculations at point $x=L-a_{2}(\mathrm{~F}=5 \mathrm{kN}$, $\mathrm{b}=120 \mathrm{~mm}, \mathrm{a}_{1}=\mathrm{a}_{2}=70 \mathrm{~mm}$ ): (a) Interface shear stress $\tau^{1,2}(x)$, (b) Interface normal stress $v^{1,2}(x)$

Figure 3. Evolution of strain energy release rate in function of the normalized crack length $\mathrm{a}_{\mathrm{f}} / \mathrm{L}_{\mathrm{F}}\left(\right.$ for $\mathrm{F}_{\text {Type } \mathrm{I}}=$ $12 \mathrm{kN}$, for $\mathrm{F}_{\text {Type II }}=5 \mathrm{kN}, \mathrm{E}^{1} / \mathrm{E}^{2}=17.4, \mathrm{~b}=120 \mathrm{~mm}, \mathrm{a}_{1}=\mathrm{a}_{2}=70 \mathrm{~mm}$ ): (a) Comparison of the two methods: energy and VVCT; (b) $\mathrm{G}_{\mathrm{I}}$ and $\mathrm{G}_{\mathrm{II}}$ strain energy release rate compared to the total $\mathrm{G}$.

Figure 4. Effect of Young modulus ratio between layers $\left(F=5 \mathrm{kN}, \mathrm{a}_{1}=\mathrm{a}_{2}=70 \mathrm{~mm}, \mathrm{~b}=120 \mathrm{~mm}\right)$ : (a) on the tensile stress at the bottom of layer 2, (b) on the interface normal stress $v^{1,2}\left(L-a_{2}\right)$ and the shear stress $\tau^{1,2}\left(L-a_{2}\right)$

Figure 5. Variation effect of length $\mathrm{a}_{2}\left(\mathrm{E}^{2} / \mathrm{E}^{1}=17.4, \mathrm{~F}=5 \mathrm{kN}, \mathrm{a}_{1}=40 \mathrm{~mm}, \mathrm{~b}=120 \mathrm{~mm}\right)$ : (a) on the tensile stress at the bottom of the cement concrete layer, (b) on the normal stress $v^{1,2}\left(L-a_{2}\right)$ and the shear stress $\tau^{1,2}\left(L-a_{2}\right)$

Figure 6. (a) Four-point bending test arrangement (b) First debonding observations of Type I specimen (IPT-2-3 under load controlled condition 100N/s)

Figure 7. Visual debonding fracture aspect of Type I specimen: a) I-PT-2-3 b) I-PT-1-3

Figure 8. Bending parasite failures at the: a) Middle of the beam (I-PT-3-2) b) Edge of layer 2 due to non regular thickness of layers (Type I-PT-2.1 example)

Figure 9. Typical debonding fracture aspect of Type II specimen (II-PT-2-2)

Figure 10. Load versus midspan deflection curves of bi-layer specimen tested under controlled displacement rate $(0.7 \mathrm{~mm} / \mathrm{min})$

Figure 11. Load strain results for bilayer specimens tested under controlled displacement conditions $(0.7 \mathrm{~mm} / \mathrm{min})$

Figure 12. Load displacement results for bi-layer specimen tested under a lower temperature fixed at $5^{\circ} \mathrm{C}$ and a controlled displacement rate $(0.7 \mathrm{~mm} / \mathrm{min})$

Figure 13. Different failure scenarios of the bilayered 4 pt bending test for pavement material 

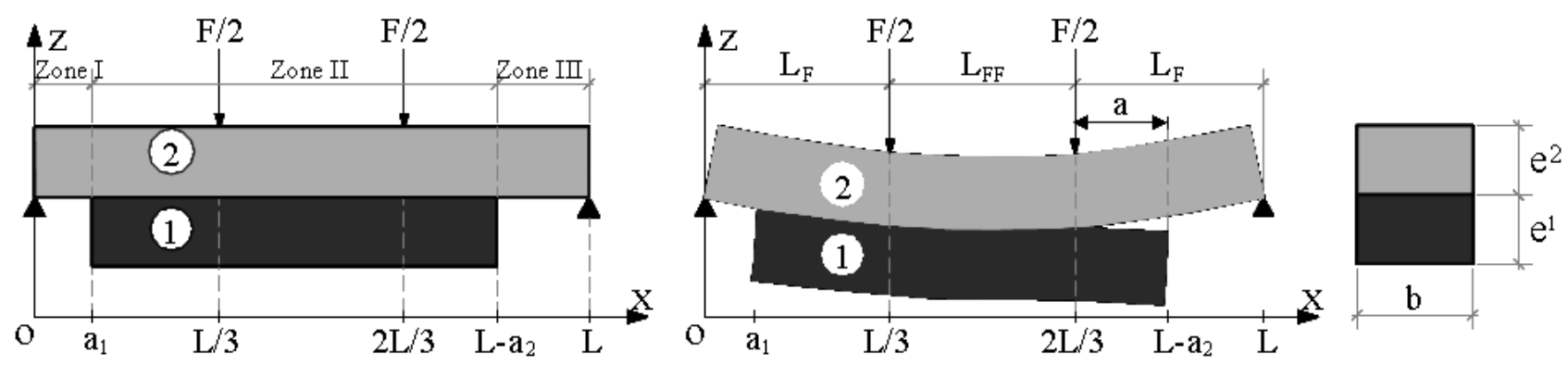

Figure 1. (a) Four-point bending test on bilayer materials (b) anti-symmetrical debonding case
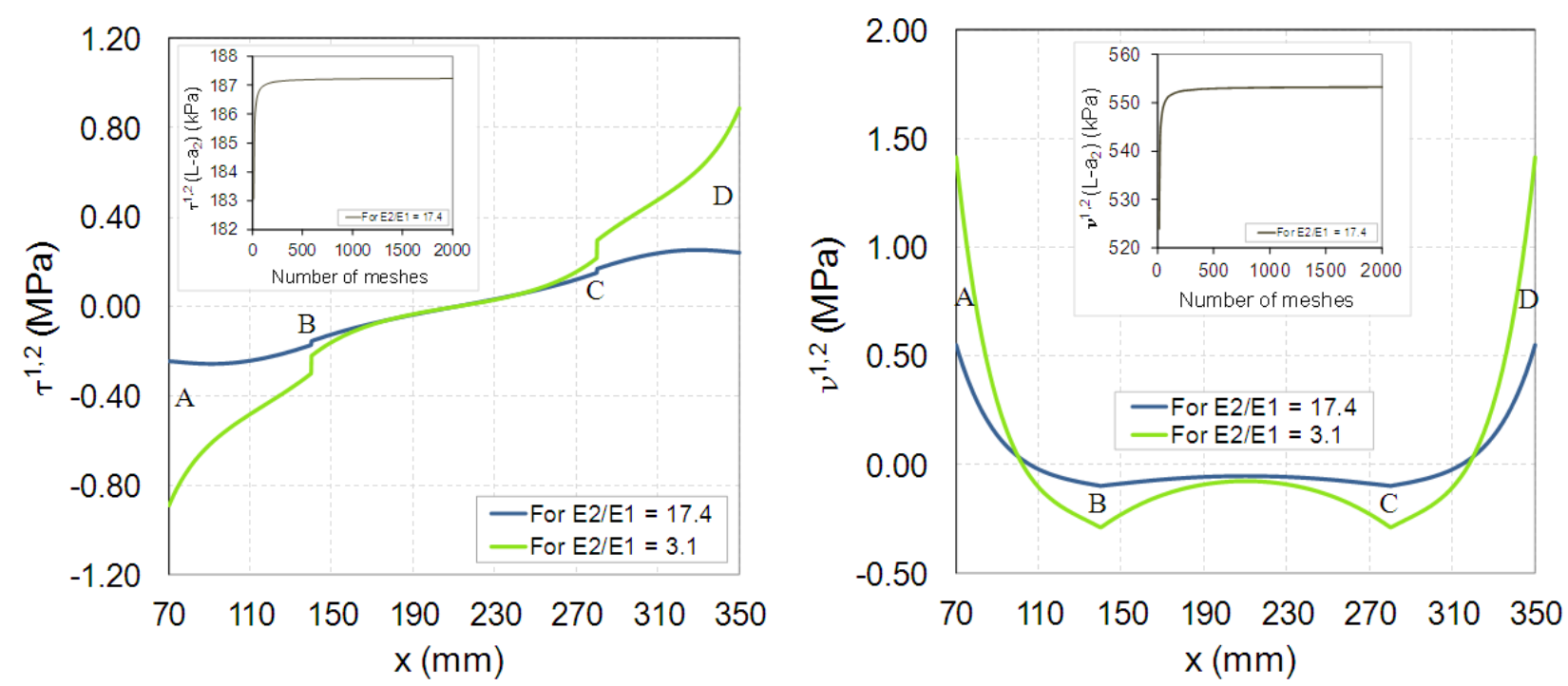

Figure 2. Interface M4-5n stresses and numerical convergence of calculations at point $x=L-a_{2}(\mathrm{~F}=5 \mathrm{kN}$, $\mathrm{b}=120 \mathrm{~mm}, \mathrm{a}_{1}=\mathrm{a}_{2}=70 \mathrm{~mm}$ ): (a) Interface shear stress $\tau^{1,2}(x)$, (b) Interface normal stress $v^{1,2}(x)$
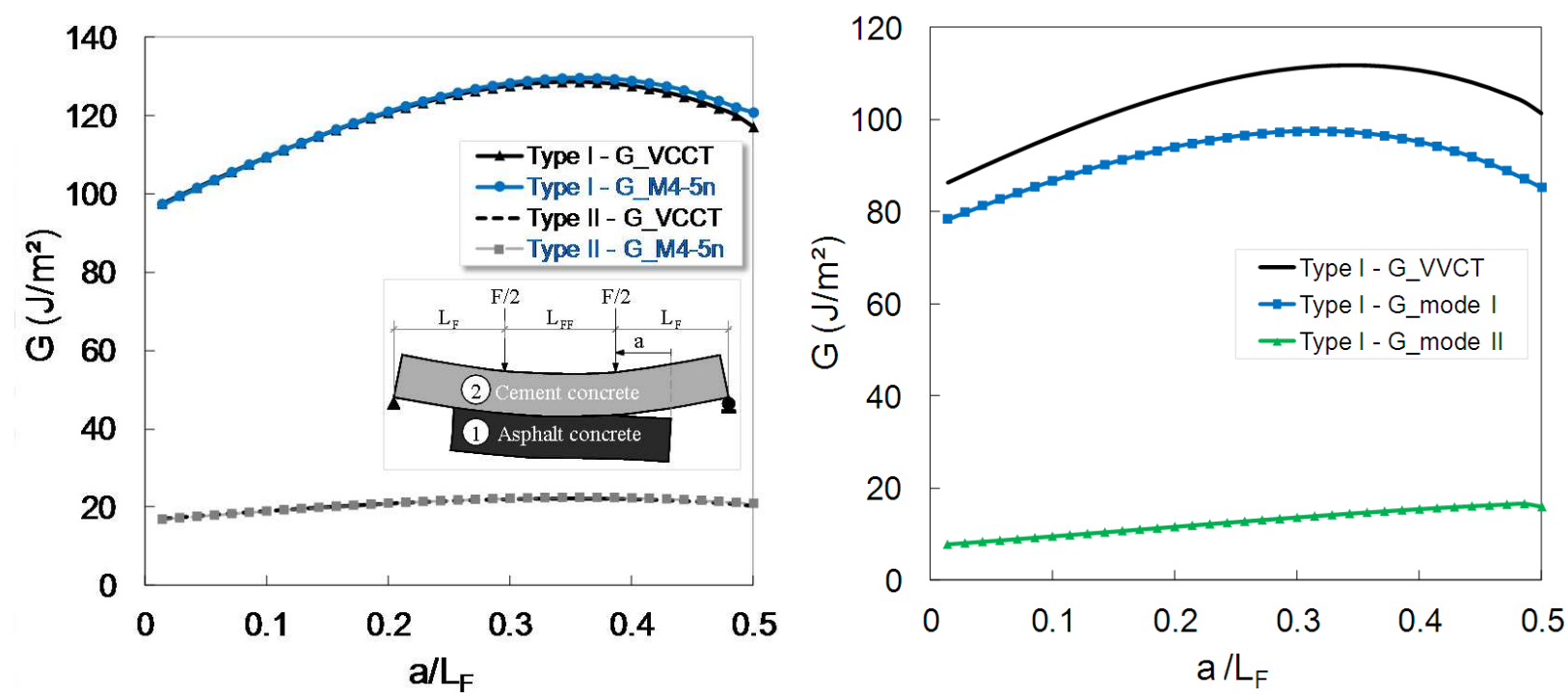

Figure 3. Evolution of strain energy release rate in function of the normalized crack length $\mathrm{a}_{\mathrm{f}} / \mathrm{L}_{\mathrm{F}}\left(\right.$ for $\mathrm{F}_{\text {Type } \mathrm{I}}=$ $12 \mathrm{kN}$, for $\mathrm{F}_{\text {Type II }}=5 \mathrm{kN}, \mathrm{E}^{1} / \mathrm{E}^{2}=17.4, \mathrm{~b}=120 \mathrm{~mm}, \mathrm{a}_{1}=\mathrm{a}_{2}=70 \mathrm{~mm}$ ): (a) Comparison of the two methods: energy and VVCT; (b) $\mathrm{G}_{\mathrm{I}}$ and $\mathrm{G}_{\mathrm{II}}$ strain energy release rate compared to the total $\mathrm{G}$. 

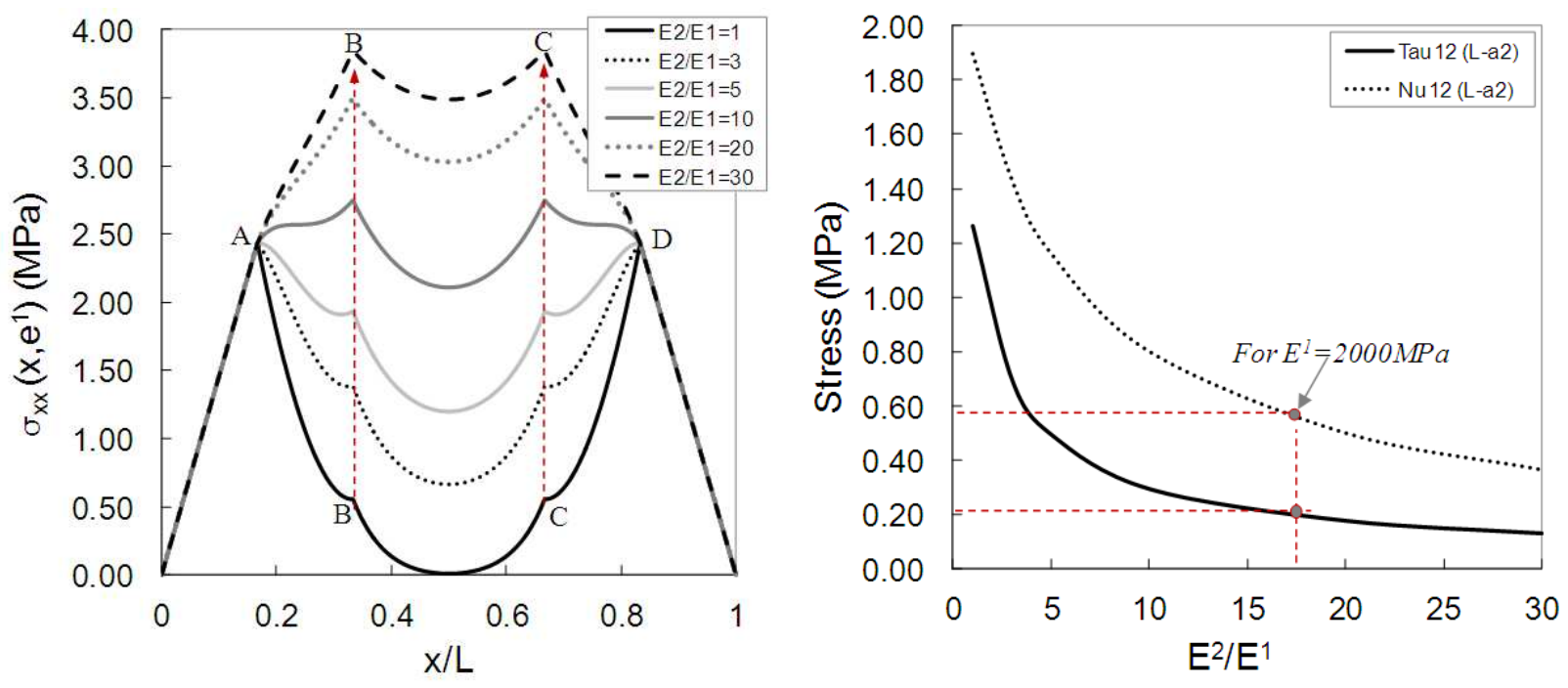

Figure 4. Effect of Young modulus ratio between layers $\left(F=5 \mathrm{kN}, \mathrm{a}_{1}=\mathrm{a}_{2}=70 \mathrm{~mm}, \mathrm{~b}=120 \mathrm{~mm}\right)$ : (a) on the tensile stress at the bottom of layer 2, (b) on the interface normal stress $v^{1,2}\left(L-a_{2}\right)$ and the shear stress $\tau^{1,2}\left(L-a_{2}\right)$
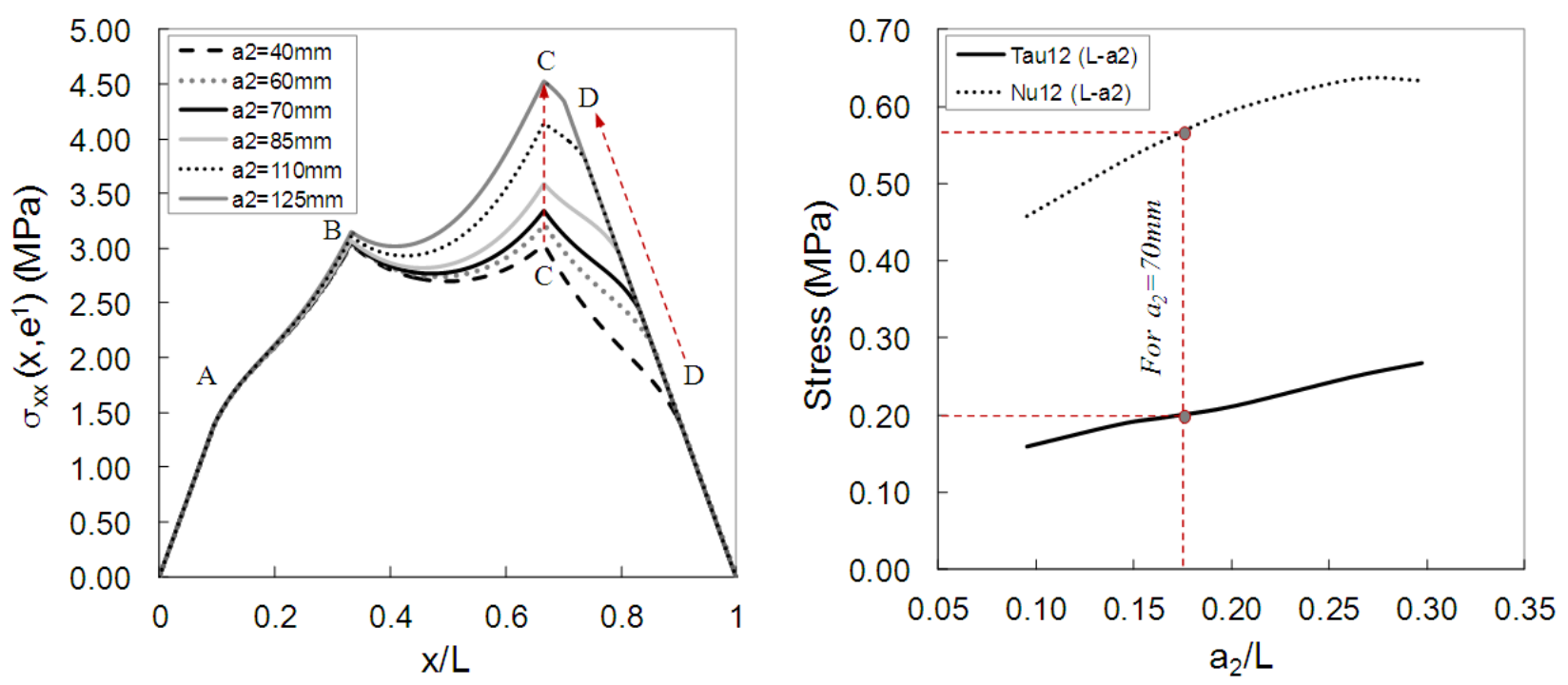

Figure 5. Variation effect of length $\mathrm{a}_{2}\left(\mathrm{E}^{2} / \mathrm{E}^{1}=17.4, \mathrm{~F}=5 \mathrm{kN}, \mathrm{a}_{1}=40 \mathrm{~mm}, \mathrm{~b}=120 \mathrm{~mm}\right)$ : (a) on the tensile stress at the bottom of the cement concrete layer, (b) on the normal stress $v^{1,2}\left(L-a_{2}\right)$ and the shear stress $\tau^{1,2}\left(L-a_{2}\right)$ 

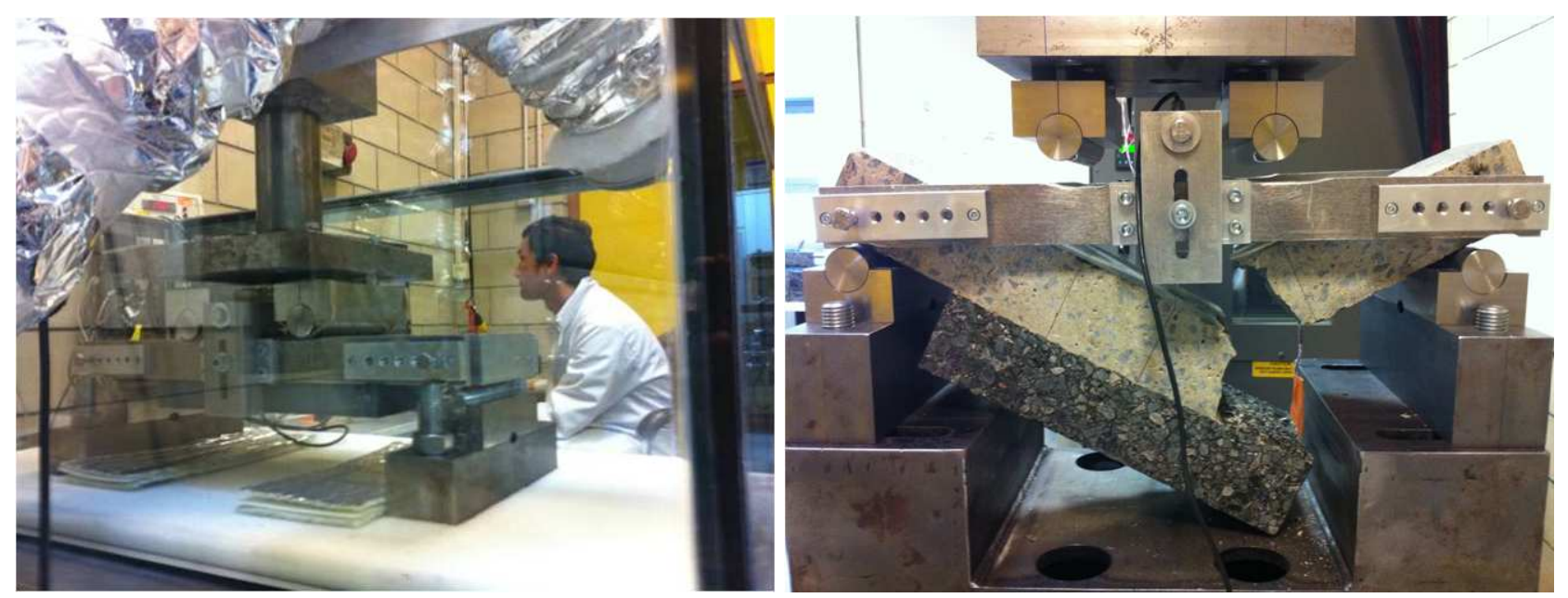

Figure 6. (a) Four-point bending test arrangement (b) First debonding observations of Type I specimen (I-

PT-2-3 under load controlled condition 100N/s)
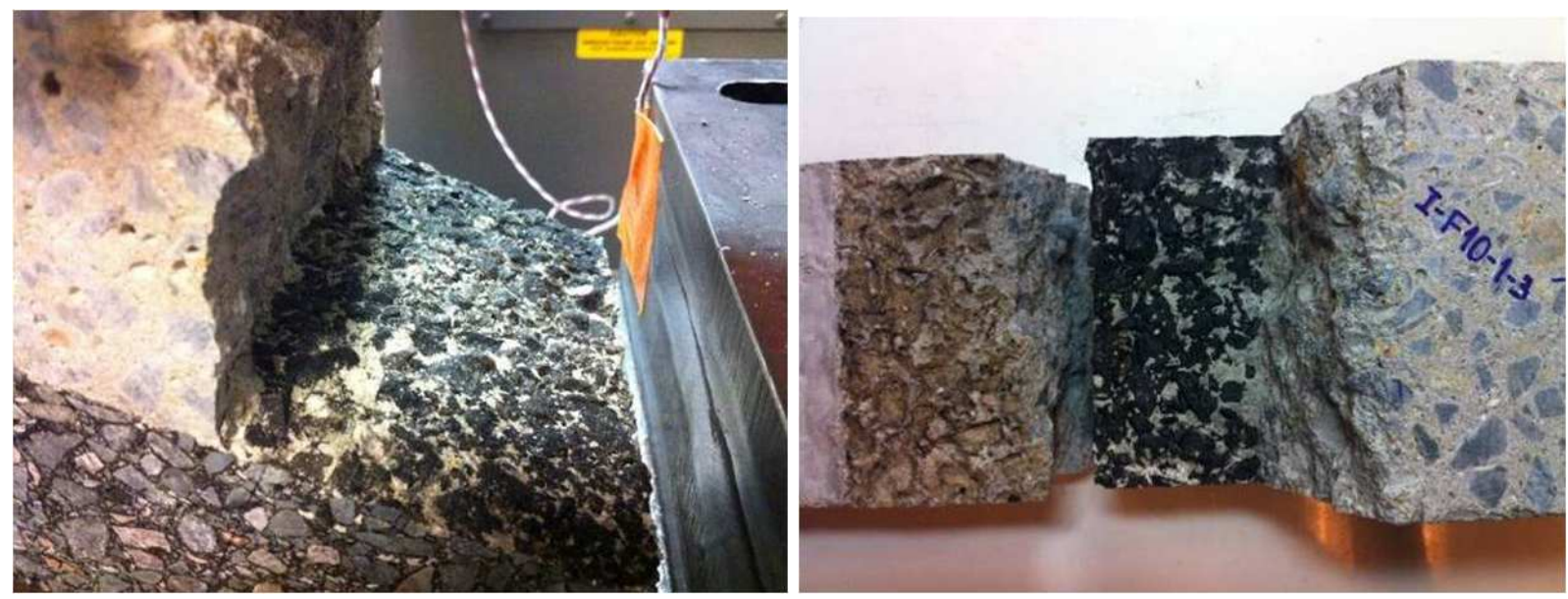

Figure 7. Visual debonding fracture aspect of Type I specimen: a) I-PT-2-3 b) I-PT-1-3
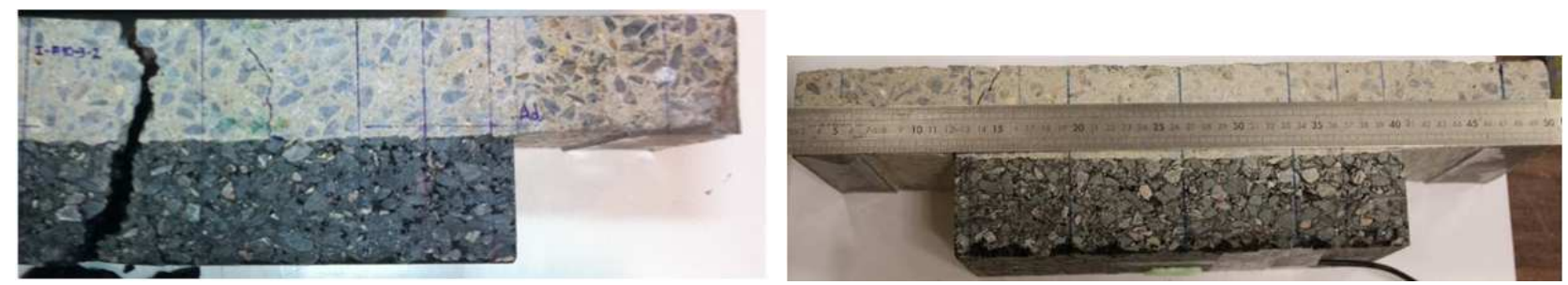

Figure 8. Bending parasite failures at the: a) Middle of the beam (I-PT-3-2) b) Edge of layer 2 due to non regular thickness of layers (Type I-PT-2.1 example) 

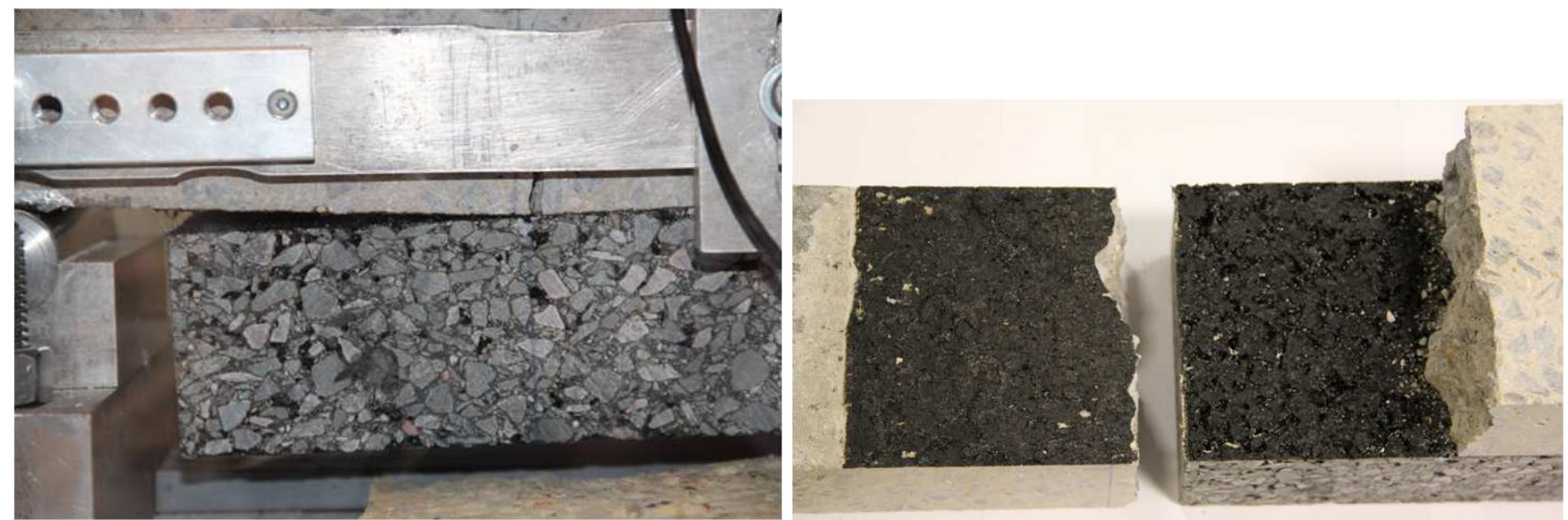

Figure 9. Typical debonding fracture aspect of Type II specimen (II-PT-2-2)

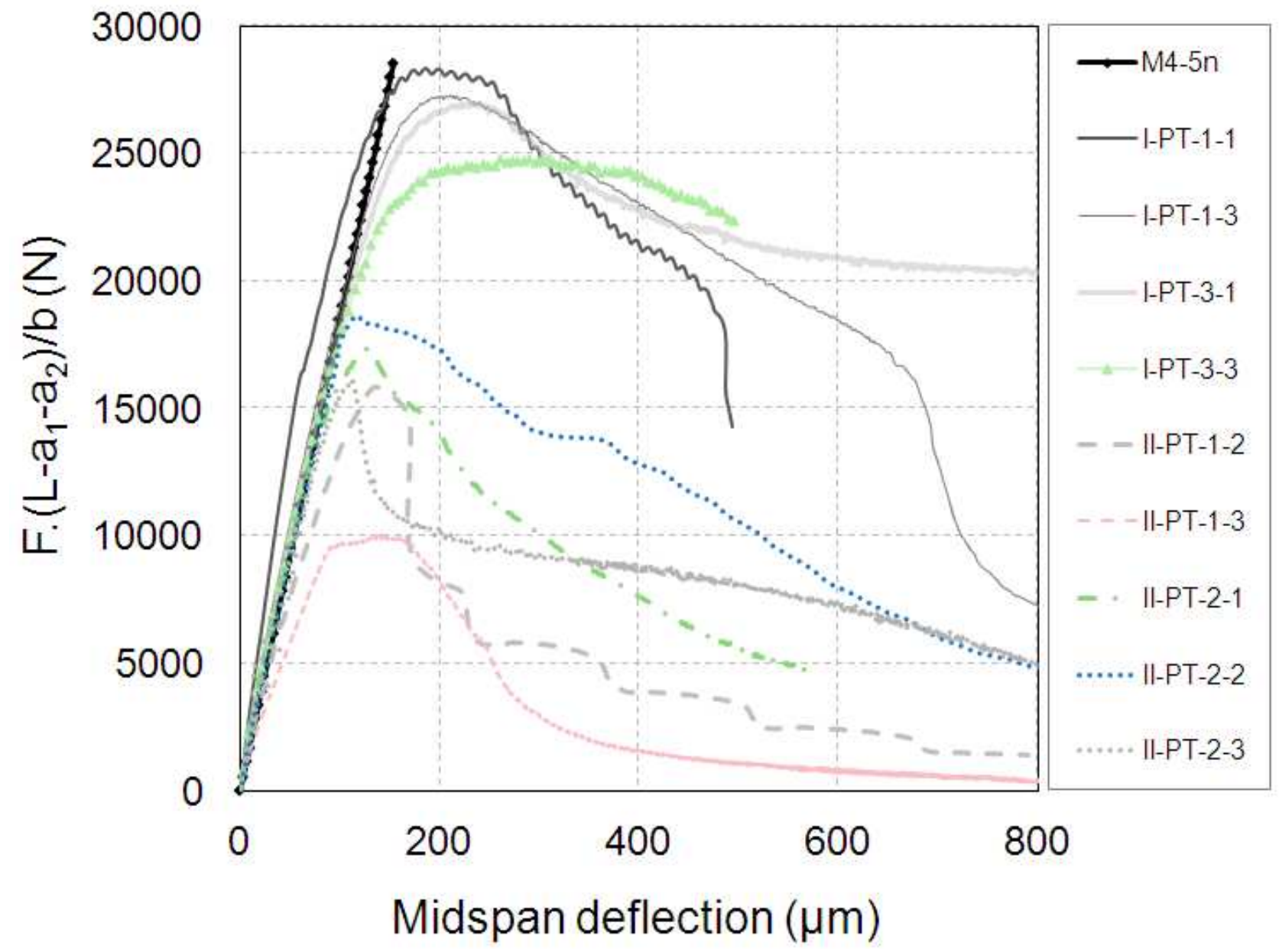

Figure 10. Load versus midspan deflection curves of bi-layer specimen tested under controlled displacement rate $(0.7 \mathrm{~mm} / \mathrm{min})$ 


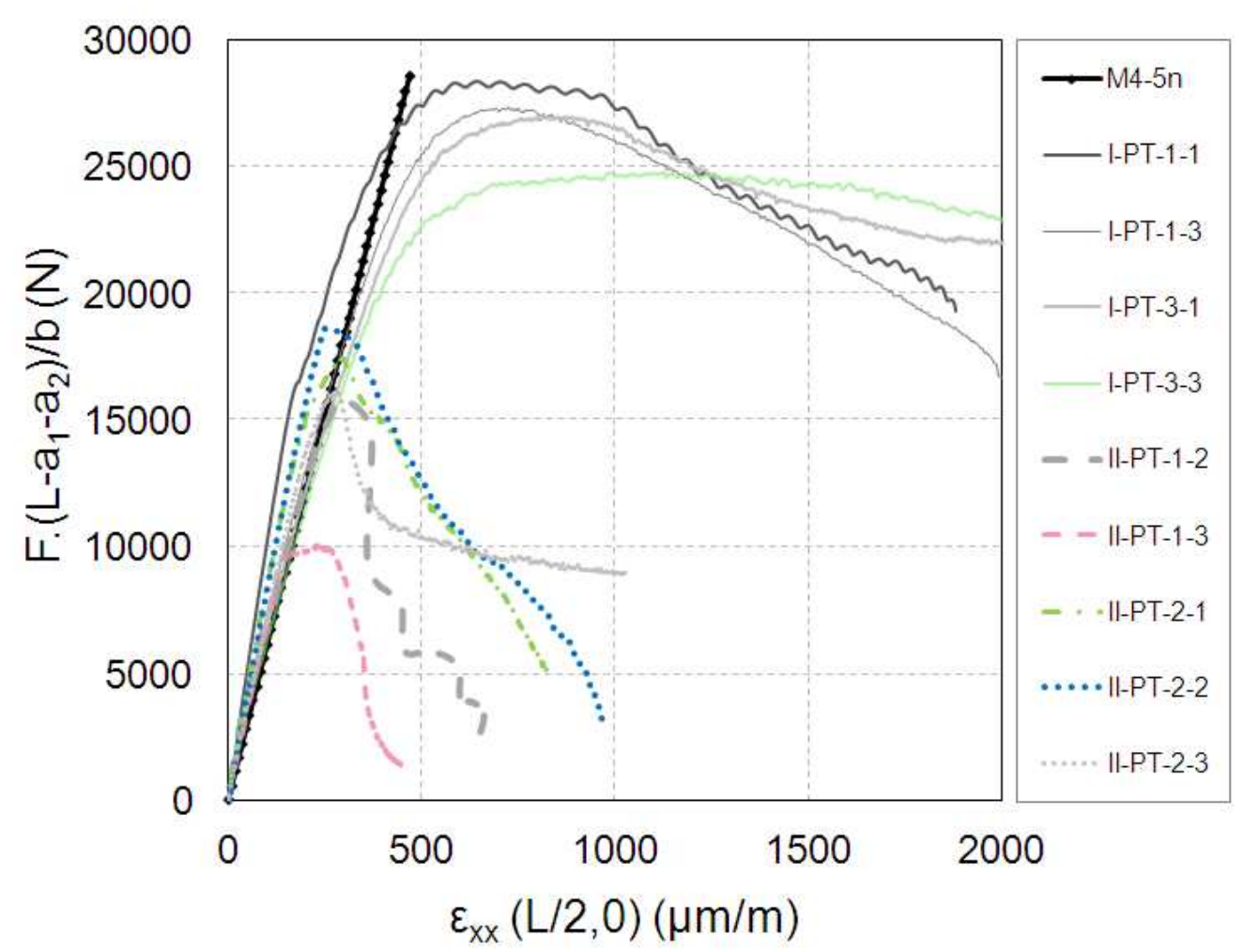

Figure 11. Load strain results for bilayer specimens tested under controlled displacement conditions $(0.7 \mathrm{~mm} / \mathrm{min})$
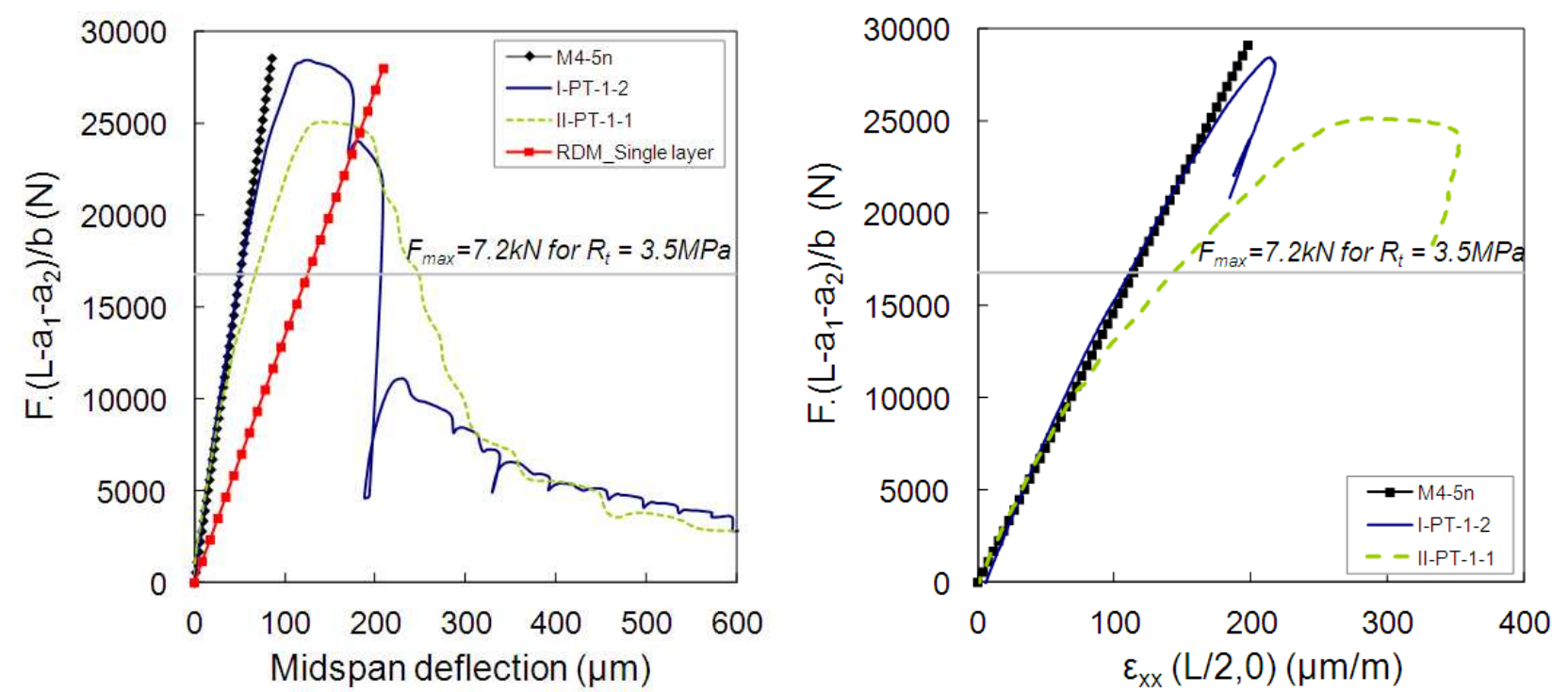

Figure 12. Load displacement results for bi-layer specimen tested under a lower temperature fixed at $5^{\circ} \mathrm{C}$ and a controlled displacement rate $(0.7 \mathrm{~mm} / \mathrm{min})$ 
Zone A : No cracking in the concrete layer nor interface debonding

Zone B : Possibility of only interface debonding or both cracking in concrete and debonding

Zone C: Failure of the concrete layer coupled with interface debonding

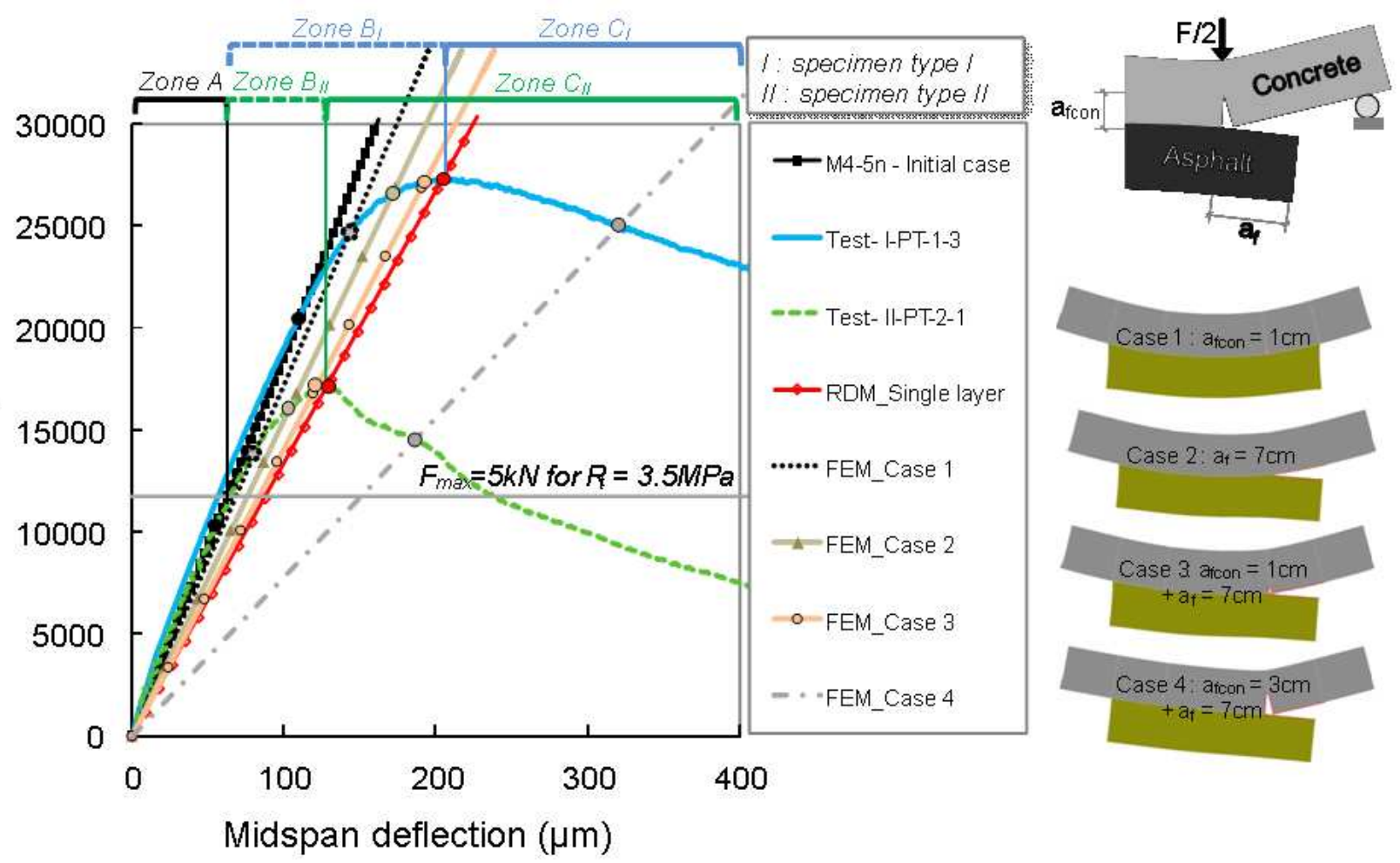

Figure 13. Different failure scenarios of the bi-layered $4 \mathrm{pt}$ bending test for pavement material 